\title{
Voltage Transients Mitigation in the DC Distribution Network of More/All Electric Aircrafts
}

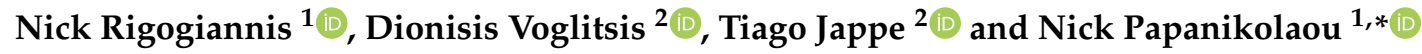 \\ 1 Department of Electrical and Computer Engineering, Democritus University of Thrace, Kimmeria ECE \\ Campus, 67132 Xanthi, Greece; nrigogia@ee.duth.gr \\ 2 Solutions Engineering Center, ON Semiconductor, 85609 Munich, Germany; \\ dionisis.voglitsis@onsemi.com (D.V.); tiago.jappe@onsemi.com (T.J.) \\ * Correspondence: npapanik@ee.duth.gr; Tel.: +30-2541-079-921
}

Received: 3 July 2020; Accepted: 6 August 2020; Published: 10 August 2020

check for updates

\begin{abstract}
The objective of this paper is to present a power conversion system, based on a bidirectional DC/DC converter, along with a supercapacitor bank, that mitigates the voltage transients that occur on the DC distribution network of More/All Electric Aircrafts. These transients, such as voltage sags and swells appear on the DC buses of on-board microgrids, mainly due to load variations and are classified according to the aircrafts electric power system standards. First, we shortly describe an aircraft distribution network, that is applicable to the most common actual aircraft architectures, then we present the proposed system, along with the bidirectional DC/DC converter design, the control technique and the supercapacitor bank sizing. Finally, we present simulation and experimental results that support the effectiveness of the proposed system to effectively compensate voltage transients, supporting the DC buses in dynamic conditions. Concluding, the proposed system provides high power quality and compliance with the respective power quality standards for aircraft microgrids.
\end{abstract}

Keywords: All Electric Aircraft; bidirectional buck-boost converter; DC microgrids; More Electric Aircraft; peak current control; power quality; supercapacitors; voltage transients

\section{Introduction}

Having in mind the development of more efficient and environmentally friendly aircrafts, the biggest aircraft manufacturers have started to incorporate the concept of More and All Electric Aircraft (M/A-AE). The main idea of M/A-AE technology is to use electric power for replacing other non-electric power sources, used in a conventional aircraft (e.g., hydraulic, mechanical or pneumatic). As such, the largest civil aircraft models, i.e., Airbus 380 and Boeing 787 both incorporate MEA technology. The total installed electric power of the latter one (B787) reaches up to $1 \mathrm{MVA}$, which makes it the aircraft with the highest electrification level nowadays [1,2]. Towards this direction, the Advisory Council for Aviation Research and Innovation in Europe is envisioning the incorporation of M/A-EA concept within the "Flightpath 2050" program which, among others, sets some very strict long-term environmental goals [3].

As the electrification level of large civil aircrafts is expected to increase in the near future, more electronically controlled loads are emerging. In this context, the aircraft electrical power system is of particular interest in all respects. Power converters are the key elements for efficient energy conversion in the distribution network of the aforementioned system. In more detail, bidirectional power converters constitute components of paramount importance for energy transactions either between the on-board microgrid buses, which may adopt different voltage characteristics (i.e., AC or DC, various voltage levels, various frequencies etc.), or between a bus and an energy storage system [4]. Considering the latter case, both long- and short-term energy storage units have been employed in 
many cases, leading so to hybrid configurations (e.g., batteries and supercapacitors) [5-7]. Thus, with an appropriate energy management scheme prioritizing the different energy sources, depending on the frequency content of the bus request, these systems are capable to face the challenging issues of power flow regulation, voltage stability and fast dynamic response [4], achieving high power quality for the M/A-EA microgrid.

In this paper, the power quality issues are focused, considering a DC-bus based electrical distribution system. The transient phenomena (e.g., voltage sags and swells) that may occur at the High Voltage DC (HVDC) bus of the distribution network are investigated, in order to design, construct and evaluate (through simulations and experiments) a power conversion system capable of mitigating these voltage transients. The aforementioned system comprises a bidirectional DC/DC converter, a supercapacitor bank and an appropriate control scheme. In contrast to the aforementioned works [5-7] that focus on a general energy management scheme, in this paper we focus on the compensation of voltage transients and as such, our system operates solely during voltage sags or swells. Hence, the primary goal of the proposed system is to provide voltage support during dynamic conditions, in order to cope with the respective power quality standards.

\section{More/All Electric Aircraft System Description}

The basic power system architecture of an aircraft is presented in Figure 1, where the main generators and auxiliary power units (APUs) are depicted, along with the power conversion and distribution system, the loads and the Solid State Power Controllers (SSPCs).

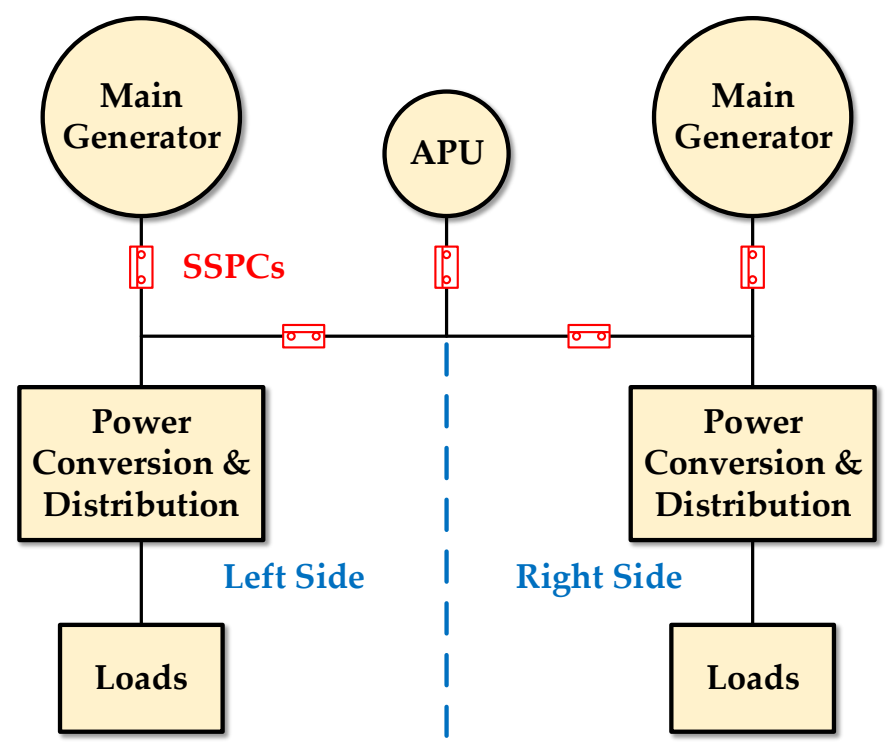

Figure 1. Basic architecture of the aircraft electric power system.

In general, there are two main generator units in an aircraft. Those are driven by combustion engines or by auxiliary power units, when the airplane is landed (Figure 1). The electric power that is generated is converted and then distributed via the distribution network of the aircraft. The main distribution system architectures, appropriate for the M/A-EA concept are described in the next subsection.

\subsection{General Description}

Regarding the distribution network architecture, the constant frequency AC distribution $(115 \mathrm{~V} / 400 \mathrm{~Hz})$ has been commonly used in conventional commercial aircrafts (e.g., A320, B737). It consists of $115 \mathrm{~V}$ AC and $28 \mathrm{~V}$ DC buses, whereas $400 \mathrm{~Hz}$ constant frequency is achieved by means of a constant speed drive [8]. 
However, the latest aircraft models (e.g., A380, B787) incorporate a hybrid AC and DC distribution architecture with $115 \mathrm{~V} / 360-800 \mathrm{~Hz}$ or $230 \mathrm{~V} / 360-800 \mathrm{~Hz}$ AC and $270 \mathrm{~V}$ or $540 \mathrm{~V}( \pm 270 \mathrm{~V}) \mathrm{DC}$. In this architecture, the heavy and inefficient constant speed drive is removed and the generator is directly connected to the engine, leading to variable frequency of the primary AC bus. Currently, this distribution architecture is considered a suitable platform for future aircrafts [9].

Additionally, a purely HVDC distribution architecture has been proposed, utilizing $270 \mathrm{~V}$ or $540 \mathrm{~V}$ $( \pm 270 \mathrm{~V}) \mathrm{DC}$ buses. This architecture is a very promising solution for future M/A-EAs and has been investigated in the context of several research projects, such as Clean Sky JU [10] and MOET EU [11]. This distribution network configuration comes also as a consequence of the emerging technology of DC microgrids [12-14]. Both the aforementioned a) hybrid and b) purely HVDC distribution network configurations are depicted in Figure 2, where TRU stands for Transformer Rectifier Unit, whereas ATRU stands for Auto-Transformer Rectifier Unit.

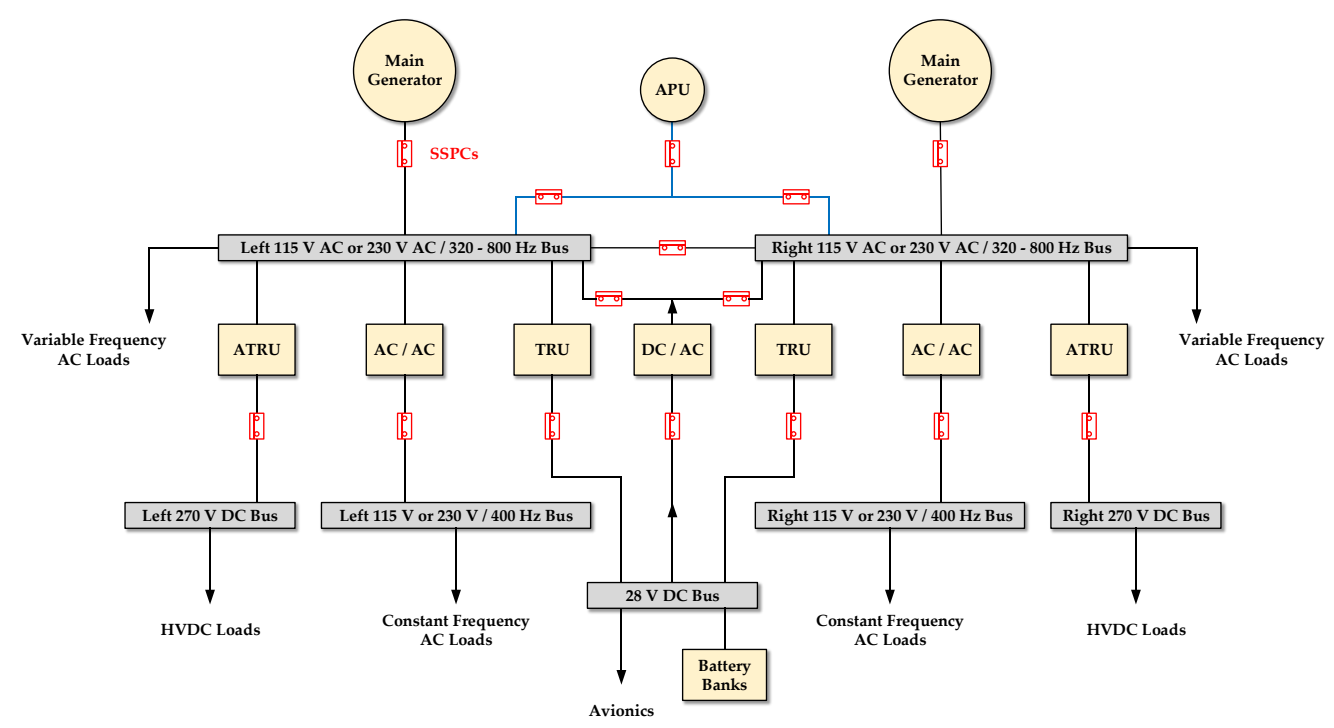

(a)

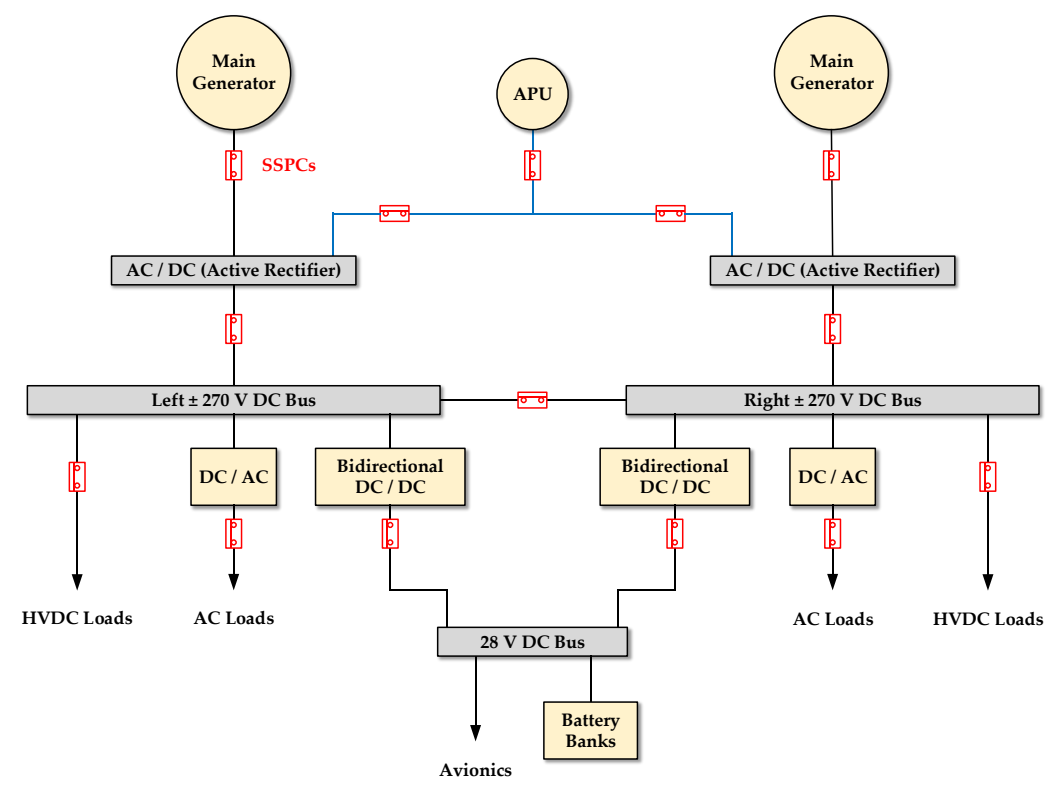

(b)

Figure 2. Proposed distribution network architectures for future aircrafts; (a) hybrid AC and DC configuration, which is used in Airbus 380 and Boeing 787 and (b) purely HVDC configuration, which is proposed within the framework of Clean Sky JU [10] and MOET EU [11]. 
The advantages of DC distribution systems, compared to their AC counterparts have been extensively presented in the scientific literature over the past few years, including higher efficiency and reliability with simpler control schemes. Furthermore, modern power systems, such as the M/A-EA distribution network, feature various electronic loads, energy storage systems and distributed power units, which are in their vast majority DC or (at least) adopt an intermediate DC-link, leading so to DC distribution architectures [12-16].

It is worth noting that the voltage transients mitigation system that we propose is based on a DC/DC converter, and thus it can be effectively integrated in both of the abovementioned distribution network architectures (which are dominant for future M/A-EAs), as they both incorporate a DC distribution network. Figure 3 depicts the incorporation of the proposed system into the DC distribution network of a M/A-EA, with hybrid or purely HVDC configuration.

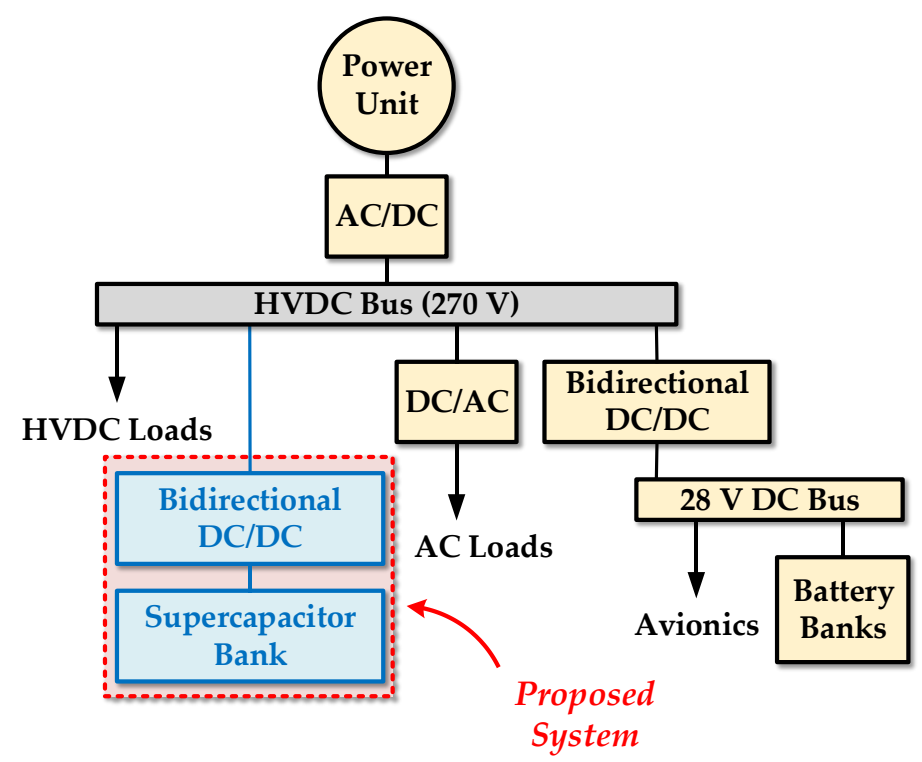

Figure 3. Incorporation of the proposed system into the HVDC bus of a M/A-EA microgrid.

\subsection{Voltage Transients}

As the electrification level of civil aircrafts is constantly increasing, load variations and intermittent operation may lead to transient phenomena and voltage disturbances which impact the DC voltage of the distribution network buses [17].

In general, a DC voltage transient usually occurs either because of normal disturbances, such as electric load steps and engine speed changes, or because of a momentary power interruption and an abnormal disturbance, such as a fault clearing. According to MIL-STD-704F [18], which is the standard for aircraft electric power characteristics, transients are classified into three categories, namely lesser, normal and abnormal transients. Lesser transients are those that do not exceed the steady state limits. Normal transients may exceed the steady state limits but they remain within the specified normal transient region. Finally, transients that exceed normal transient limits (as a result of an abnormal disturbance) and eventually return to steady state limits are defined as abnormal transients.

In this work, the proposed system aims to mitigate voltage sags and swells that occur as a result of abnormal transients, mainly because of load step changes. To do so, we propose the utilization of a DC/DC converter, along with a supercapacitor bank, to be connected to the main HVDC bus. Finally, it is worth noting that the proposed concept can be also applied in the DC network of electric vehicles or in any other DC network, the voltage level of which needs to be maintained within strict limits. 


\section{Proposed System Description}

In order to compensate the above described voltage transients, we propose a power conversion system comprising a bidirectional converter, based on the Bidirectional Buck-Boost Converter (BBBC) topology, along with a supercapacitor bank. The main components of the proposed system, for both power and control stages are described in the following subsections. Furthermore, we propose a design for hardware implementation.

\subsection{Bidirectional Buck-Boost Converter}

The DC/DC converter is the core component of the proposed compensation system and plays a vital role for the realization of the proposed concept, as it acts as the interface between the supercapacitor bank and the HVDC bus. In this regard, the BBBC topology consists a well-established DC/DC architecture and seems to be in favor for energy recovery (e.g., regenerative braking for electrical machines) and active power filtering applications, as well as various two-quadrant applications, where bidirectional power flow is imperative $[19,20]$. Moreover, it incorporates a minimum number of semiconductor switches and passive components.

The BBBC power stage is depicted in the schematic diagram of Figure 4. It consists of a semiconductor switches pair (power MOSFETs) in half-bridge configuration and an inductor connected at the bridge-leg common point. The high voltage side is connected to the HVDC bus, whereas the low voltage side is connected to the supercapacitor bank; supercapacitor technology provides ultra-high energy storage capability at low rated voltages [21]. In our application, the Silicon Carbide (SiC) power MOSFETs NVHL160N120SC1, provided by ON Semiconductor ${ }^{\circledR}$ are used. The proposed SiC switches accommodate the hard-switching behavior of the converter without requiring any heatsink or forced air cooling. As such, compact designs with very high power densities are possible. Two modes of operation are considered, according to the schematic diagram of Figure 4, namely buck or step-down (power flows from high to low voltage side-supercapacitors are charging) and boost or step-up operation (power flows from low to high voltage side-supercapacitors are discharging). In both cases, synchronous operation can be supported, because of the half-bridge configuration of the topology. If synchronous operation is not desired, then the antiparallel diode of the inactive switch operates as a freewheeling diode [22].

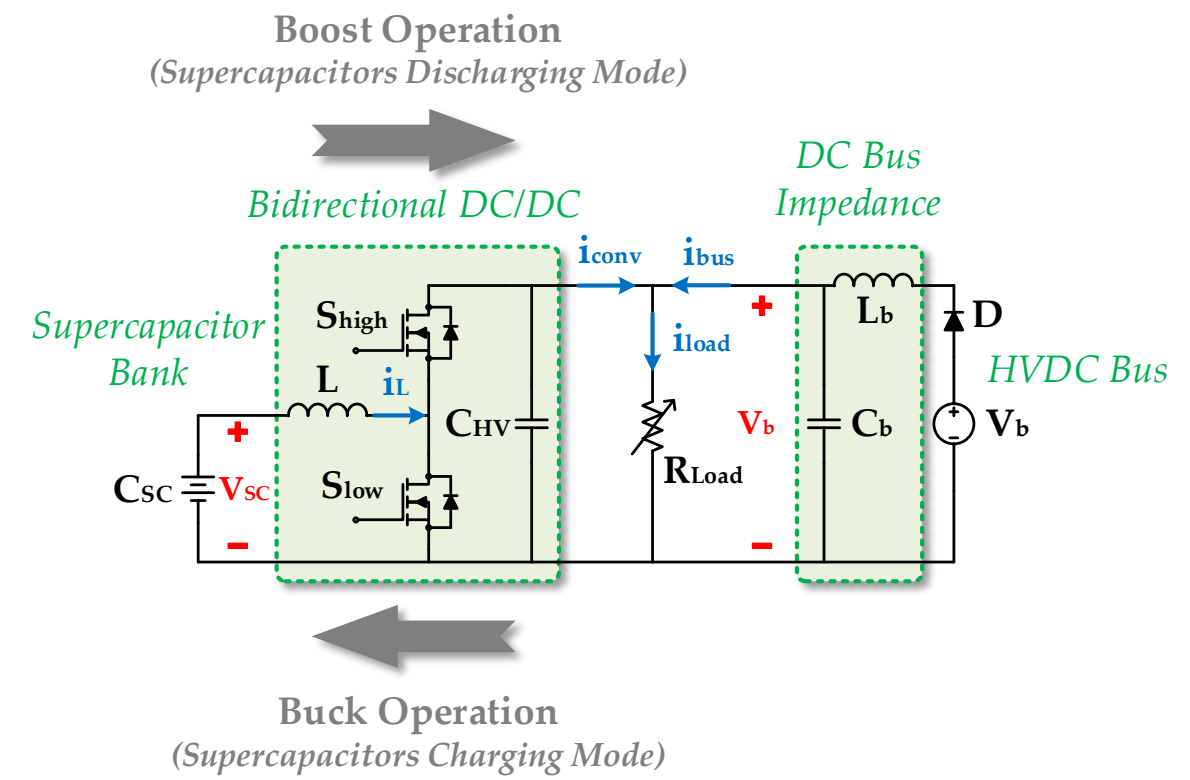

Figure 4. Schematic diagram of the proposed system and the test bench, used for simulation and experimental evaluation. 
In addition, the converter may operate either in Continuous Conduction Mode (CCM), or in Discontinuous Conduction Mode (DCM), depending on the inductor current. CCM operation results in less current ripple, hence less magnetic and turn-off losses. On the other hand, DCM operation results in increased current ripple, and hence higher magnetic, conduction and turn-off losses [21,23]. However, DCM operation requires smaller inductance value and offers faster dynamics because of the cycle-by-cycle current regulation.

In this work CCM operation along with a current controller is selected, achieving both low current ripple (thus reduced losses) and fast dynamic response. The CCM operation is designed for a wide range of operation, by properly selecting the inductance value $(L)$ and the switching frequency $\left(f_{s}\right)$ of the converter. The necessary internal current control loop is based on the Peak Current Control (PCC) method and it is digitally implemented with the aid of a microcontroller unit [22,24-26].

Finally, the driver FAN7390 by ON Semiconductor has been selected for the converter driving circuit. This driver is an excellent and cost-effective solution for the current application and it is based on the well-established bootstrap supply technique (its operating principle is described in detail in [26]). For the bootstrap driver diode, we have used the RHRD660S from ON Semiconductor, making the DC/DC converter system a complete ON Semiconductor solution.

\subsection{Supercapacitor Bank}

As for the energy storage systems, supercapacitors and battery banks are usually employed for this kind of applications. As regards the power and energy density and life time, these two energy storage technologies are characterized by opposite features [21]. Hence, in various applications they are combined, adopting so hybrid energy storage configurations.

Compared to batteries, supercapacitors provide high capacitance, higher power density, lower energy density and longer life time [21]. Owing to their aforementioned characteristics, supercapacitors are able to compensate steep voltage transients and effectively support the DC bus.

For this work, a supercapacitor bank of approximately $12.92 \mathrm{~F}$ is utilized, comprising 24 series connected supercapacitors with a capacitance and maximum voltage values of $310 \mathrm{~F}$ and $2.7 \mathrm{~V}$, respectively. As it will be shown later on, the capacity of $12.92 \mathrm{~F}$ is overwhelming for the experimental DC/DC converter design of this paper. This capacity corresponds to much higher power rating converters that we are planning to construct in the near future. For the needs of this paper, however, we used an experimental prototype which is just a scaled-down version of the final one, focusing more on the validation of the voltage sag/swell mitigation concept, and not so much on the converter and system design.

\subsection{Control Technique}

As regards the control scheme, it is based on the load current monitoring and the decoupling of its high-frequency component via a digitally implemented Low-Pass Filter (LPF), so as the proposed converter to operate solely during voltage transients. In order to identify the voltage transient, given the fact that the real-time DC bus generator current is an unavailable parameter, the load current measurement is used. The high-frequency current component is decoupled from the mean value, by means of the LPF. The cutoff frequency $\left(f_{c}\right)$, which is a parameter of major importance for the design of the control scheme, depends on the time constants of the DC bus generator (i.e., electrical and mechanical characteristics), which are modeled via an equivalent impedance for the DC bus. Thus, the appropriate $f_{c}$ values may be effectively determined via simulations for the proposed system. Three values are finally selected $(1 \mathrm{~Hz}, 2 \mathrm{~Hz}$ and $5 \mathrm{~Hz})$, and the system dynamic performance is evaluated via both simulations and experiments, in respect to the aforementioned $f_{c}$ values. As it will be shown later on (in Section 4), the $1 \mathrm{~Hz}$ value for the LPF cutoff frequency is superior to the $2 \mathrm{~Hz}$ and $5 \mathrm{~Hz}$ cases, providing effective voltage support and compliance with the MIL-STD-704F power quality characteristics. The block diagram of the proposed control scheme is given in Figure $5 ; k$-factor is elaborated next; the compensation ramp calculation process is elaborated in Appendix A. 


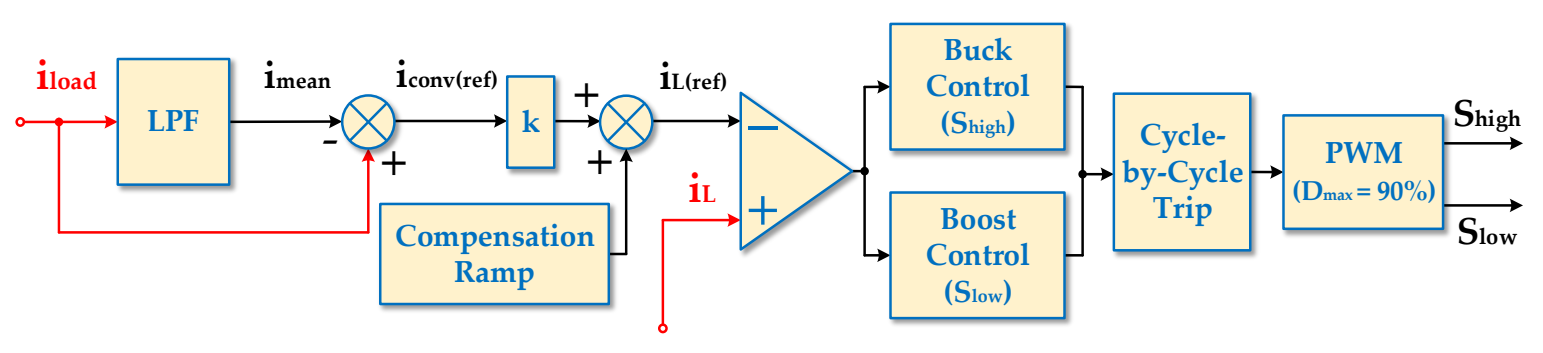

Figure 5. Block diagram of the proposed control scheme.

In more detail, for the control block diagram the power converter current reference is derived, after the subtraction of the filtered current value from the actual current value. During normal operation the result of this subtraction is approximately zero. On the other hand, during transient phenomena the output of the filter differs from the actual current value. That difference is used as the input reference current for the BBBC. During transients, the BBBC has to source (positive reference provided by the control scheme) or sink (negative reference provided by the control scheme) current during the transient state, in order to effectively mitigate the voltage transients. In other words, the BBBC has to provide the amount of current that the DC bus generators cannot support, due to their relatively slow time response constants.

Apparently, the proposed control scheme is in principal a current controller for the inductor current, based on the well-established PCC technique. In order to maintain a linear relation between the input reference current of the BBBC and its output current, the converter is designed for CCM operation with low $(<5 \%)$ inductor current ripple. In that way, the output current of the converter is linearly linked to the inductor current (in both the boost and the buck mode) by the factor of the input/output voltages ratio. In more detail, considering steady state operation and CCM, the transfer functions for boost (1) and buck (2) modes are given below [27]:

$$
\begin{gathered}
\frac{V_{H I G H}}{V_{\text {LOW }}}=\frac{1}{1-d}, \\
\frac{V_{\text {LOW }}}{V_{\text {HIGH }}}=d,
\end{gathered}
$$

where $d$ stands for the duty ratio of the converter primary switch (in each case), whereas $V_{H I G H}$ and $V_{L O W}$ refer to the average voltage values, for the high voltage and low voltage side, respectively. The converter may operate either in buck mode or in boost mode, thus the terms "input" and "output" are not preferred here, as they may be confusing. Assuming zero power losses (i.e., ideal components) and that the switching period $\left(T_{S}\right)$ is much smaller than the disturbance time interval (i.e., transient due to load step change), it can be assumed that:

$$
\begin{gathered}
P_{\text {HIGH }}=P_{\text {LOW }} \\
V_{\text {HIGH }} \cdot I_{\text {HIGH }}=V_{\text {LOW }} \cdot I_{\text {LOW }},
\end{gathered}
$$

where $P_{H I G H}, P_{L O W}$ and $I_{H I G H}, I_{L O W}$ are the power and current average values over a switching cycle, referring to the high and low voltage side respectively. Rearranging (4), it is easy to acquire:

$$
\frac{V_{H I G H}}{V_{L O W}}=\frac{I_{L O W}}{I_{H I G H}} .
$$


However, according to Figure 4, the average value of the low side current $\left(I_{L O W}\right)$ equals to the average value of the inductor current $\left(I_{L}\right)$. In addition, in cases of low current ripple, the peak inductor current is almost equal to the mean value. Thus, the following expression is derived:

$$
\frac{V_{H I G H}}{V_{L O W}}=\frac{I_{L}}{I_{H I G H}} .
$$

Hence, for both boost and buck modes, the mean value of the inductor current is calculated, as:

$$
I_{L}=\left(\frac{V_{H I G H}}{V_{L O W}}\right) I_{H I G H} .
$$

And thus:

$$
k=\frac{V_{H I G H}}{V_{L O W}} .
$$

As such, it should be noted that the reference current that is generated by the aforementioned subtraction has to be firstly multiplied by the converter ratio $(k)$ and then to be used as the inductor current reference for the BBBC. A more detailed description of PCC is given in the following paragraph.

The principle of PCC is based on the determination of the on-time interval of the primary converter switch, by the rise of the inductor current up to its predetermined reference peak value. As for the advantages of this method, the inherent fault protection, due to the limit in the inductor peak current value, as well as the fast-dynamic response and relatively simple feedback compensation (in case of an outer control loop), make PCC one of the most popular solutions for DC/DC conversion applications. In addition, the adoption of synchronous rectification operation, (which may increase the overall converter efficiency) is feasible, whereas filter design for the input and the output stages becomes simpler, due to the constant switching frequency that PCC employs. On the other hand, the drawback of subharmonic oscillations is common in both step-up and step-down DC/DC converters operating in CCM under current-mode control. However, these oscillations are successfully damped with the addition of a compensation ramp (which is actually a saw-tooth waveform with negative slope), with properly calculated slope, to the control signal [22]. The procedure of the slope calculation for a properly designed compensation ramp is presented in detail in Appendix A.

The above control concept is digitally implemented with the aid of a microcontroller, whereas it is noted that a higher-level control loop is also applied. This high-level controller is a supervisor, responsible for the energy management of the supercapacitors. It supervises the charge level and regulates the bidirectional converter to charge/discharge them accordingly. Eventually, the energy management scheme task is to maintain the supercapacitors voltage within a predefined region, so as the converter to effectively operate in both boost and buck modes and effectively mitigate both voltage sags and swells.

\subsection{Power Losses Analysis}

In order to estimate the energy losses as accurately as possible, during the operation of the proposed system, a power losses analysis is performed in this subsection. The total power losses $\left(P_{\text {losses }}\right)$ are distinguished into three individual terms, that is the supercapacitor bank losses $\left(P_{\text {scaps }}\right)$, i.e., conduction losses coming from the supercapacitors ESR (Equivalent Series Resistance), the BBBC inductor copper losses $\left(P_{\text {ind }}\right)$ and the semiconductor losses $\left(P_{\text {semi }}\right)$, i.e., power losses (both conduction and switching) coming from the BBBC semiconductor switches [23]. It is noted that the inductor ferrite core magnetic losses are omitted, as they constitute a minimum amount of the total power losses, in our application, due to the limited high frequency current ripple. 
Hence, the expression for the power losses is given in Equation (9):

$$
P_{\text {losses }}=P_{\text {scaps }}+P_{\text {ind }}+P_{\text {semi }}
$$

As regards the supercapacitors and the inductor power losses, it is obtained:

$$
\begin{gathered}
P_{\text {scaps }}=i_{L, r m s}^{2} \cdot R_{\text {scaps }}, \\
P_{\text {ind }}=i_{L, r m s}^{2} \cdot R_{L},
\end{gathered}
$$

where $R_{\text {scaps }}$ is the supercapacitors ESR value, $R_{L}$ is the inductor parasitic resistance, and $i_{L, r m s}$ is the RMS (Root Mean Square) value of the inductor current, which flows through the supercapacitors as well, as they are connected to the low voltage side (Figure 4).

As for the semiconductor switches ( $\mathrm{SiC}$ power MOSFETs) losses, these are divided into two components, i.e., the conduction losses $\left(P_{\text {cond }}\right)$ and the switching losses $\left(P_{s w}\right)$, which are calculated individually. Regarding the conduction losses, both the primary (i.e., $S_{\text {high }}$ for buck operation or $S_{\text {low }}$ for boost operation) MOSFET losses and the conduction losses from the antiparallel diode of the auxiliary (i.e., $S_{\text {low }}$ for buck operation or $S_{\text {high }}$ for boost operation) MOSFET are included. Hence, it is acquired:

$$
\begin{gathered}
P_{\text {semi }}=P_{\text {cond }}+P_{s w}, \\
P_{s w}=P_{t u r n-o n}+P_{\text {turn-off }} .
\end{gathered}
$$

According to [23], the conduction losses can be expressed as:

$$
\begin{aligned}
& P_{\text {cond }}=\left(I_{D, r m s}^{2} \cdot R_{D S(o n)}\right)+\left[I_{D} \cdot \Delta V_{o n} \cdot(1-d)\right] \\
& =\left(I_{D} \sqrt{d}\right)^{2} \cdot R_{D S(o n)}+\left[I_{D} \cdot \Delta V_{o n} \cdot(1-d)\right] \\
& =I_{D}\left[\left(I_{D} \cdot R_{D S(o n)} \cdot d\right)+\Delta V_{o n} \cdot(1-d)\right]
\end{aligned}
$$

where $I_{D}$ equals to the MOSFET current during its on-time interval, $R_{D S(o n)}$ is the drain-source on-resistance, $\Delta V_{o n}$ is the voltage drop of the MOSFET antiparallel diode during its conduction and $d$ stands for the duty ratio. The drain-source resistance value depends on the gate-source driving voltage (i.e., $15 \mathrm{~V}$ in this application) and it has been calculated according to the SiC MOSFET datasheet [28].

As for the switching losses, they are calculated separately for the MOSFET turn-on and turn-off transitions (Equation (13)); the turn-on losses include both the controlled (primary) MOSFET losses and the antiparallel diode of the auxiliary switch losses, owing to the reverse recovery phenomenon [23]. In other words, the diode stored charge induces additional transistor switching losses, as it is depicted in Figure 6. It is noted that in our application, non-synchronous operation is considered. The amount of the recovered stored charge $\left(Q_{r}\right)$, which is used in the following Equations (15) and (19), can be defined as the integral of the antiparallel diode current over the $t_{r}$ time interval, which corresponds to the duration of the reverse recovery process [23] and it is available in the NVHL160N120SC1 SiC MOSFET datasheet [28]. 


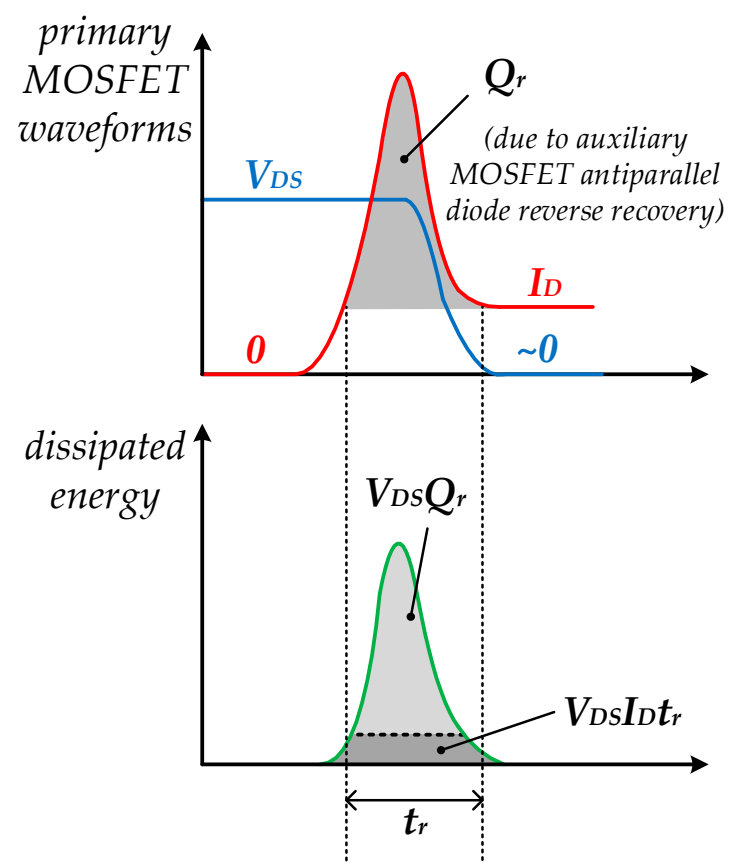

(a)

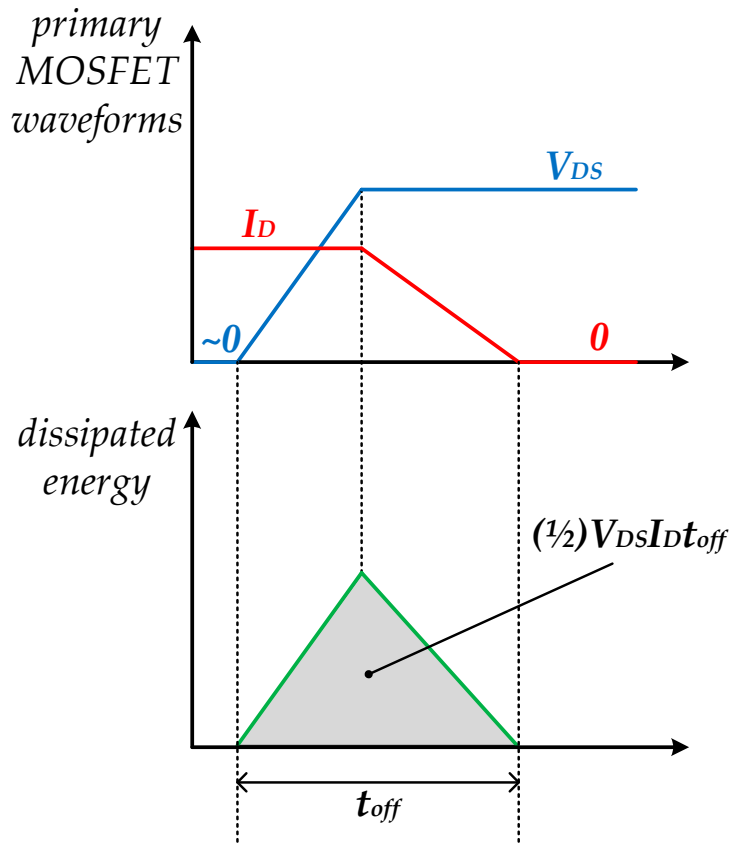

(b)

Figure 6. Switching losses calculation; (a) turn-on transition, (b) turn-off transition.

According to [23] and the qualitative representation of switches transitions in Figure 6, the energy being dissipated during the turn-on transition is calculated as:

$$
E_{o n}=V_{D S} \cdot I_{D} \cdot t_{r}+V_{D S} \cdot Q_{r}+\frac{1}{4} V_{D S} \cdot Q_{r},
$$

where $V_{D S}$ is the MOSFET (drain-source) voltage during its off-time interval, whereas $t_{r}$ is the duration of the turn-on transition. It is also noted that the amount $(1 / 4) \cdot V_{D S} \cdot Q_{r}$ corresponds to the diode switching losses. Hence, it is obtained:

$$
P_{\text {turn-on }}=E_{\text {on }} \cdot f_{s}
$$

where $f_{s}$ represents the switching frequency.

For the turn-off transition, the calculation mechanism is similar, although without the reverse recovery losses. The dissipated energy can be calculated similarly, in respect to Figure 6, as:

$$
E_{o f f}=\frac{1}{2} \cdot V_{D S} \cdot I_{D} \cdot t_{o f f},
$$

where $t_{\text {off }}$ is the duration of the turn-off transition. Hence, it is derived:

$$
P_{\text {turn-off }}=E_{o f f} \cdot f_{s} .
$$

It is worth noting that the voltage and current rise/fall times are calculated according to the MOSFET rise, fall and delay times [28], in order to obtain $t_{r}$ and $t_{\text {off }}$ time intervals. Finally, by substituting Equations (10), (11), (14), (16) and (18) into Equation (9), the total power losses are obtained:

$$
P_{\text {losses }}=i_{L, r m s}^{2}\left(R_{\text {scaps }}+R_{L}\right)+I_{D}\left[\left(I_{D} \cdot R_{D S(o n)} \cdot d\right)+\Delta V_{o n} \cdot(1-d)\right]+\left[V_{D S} I_{D}\left(t_{r}+\frac{t_{o f f}}{2}\right)+\frac{5}{4} V_{D S} Q_{r}\right] f_{s}
$$


As current and voltage waveforms change rapidly (as it will be shown in the following section) during the operation of the proposed system, it is reasonable for the system energy losses to be calculated with the aid of simulations. As such, taking into account all the aforementioned parameters, the SiC MOSFET datasheet and the components actual values (which are presented in Table 1), the energy losses are estimated via simulations; results are presented in the following section. It is noted that the energy losses and system efficiency have been calculated in boost mode of operation of the BBBC (voltage sag case), considering the worst-case scenario of no compensation ramp (equivalent to zero slope value, meaning that the subharmonic oscillations remain), which leads to a constant peak current reference, at its maximum value. In parallel, the impact of the LPF cutoff frequency selection is evaluated, by presenting energy losses for various $f_{\mathcal{c}}$ values.

Table 1. Main test bench components and system parameters.

\begin{tabular}{|c|c|}
\hline Symbol-Description & Value-(Manufacturer) \\
\hline \multicolumn{2}{|c|}{ Bidirectional Converter } \\
\hline$f_{s}$ (switching frequency) & $50 \mathrm{kHz}$ \\
\hline$L$ (inductance) & $940 \mu \mathrm{H}$ \\
\hline$R_{L}$ (inductor parasitic resistance) & $540 \mathrm{~m} \Omega$ \\
\hline$C_{H V}($ high-voltage side capacitance) & $600 \mu \mathrm{F}($ WÜRTH $)$ \\
\hline Converter switches ( $\mathrm{SiC}$ power MOSFETs) & NVHL160N120SC1 (ON) [28] \\
\hline \multicolumn{2}{|c|}{ Driving, Sensing and Control } \\
\hline Bootstrap driver & FAN7390 (ON) [29] \\
\hline Bootstrap capacitor & $10 \mu \mathrm{F}(\mathrm{YAGEO})$ \\
\hline Bootstrap diode & RHRD660S (ON) [30] \\
\hline Optocouplers & 6N137M (ON) [31] \\
\hline Current sensors & LTS-25 NP (LEM) \\
\hline \multicolumn{2}{|c|}{ Supercapacitor Bank } \\
\hline$C_{S C}$ (supercapacitors capacitance) & 12.92 F (MAXWELL) \\
\hline$R_{\text {scaps }}$ (supercapacitors ESR) & $52.8 \mathrm{~m} \Omega$ \\
\hline$V_{s c(\max )}$ (supercapacitors maximum voltage) & $64.8 \mathrm{~V}$ \\
\hline \multicolumn{2}{|l|}{ DC Bus } \\
\hline$V_{b}$ (DC bus voltage) & $120 \mathrm{~V}$ \\
\hline$L_{b}(\mathrm{DC}$ bus inductance $)$ & $100 \mathrm{mH}$ \\
\hline$R_{b}(\mathrm{DC}$ bus resistance $)$ & $900 \mathrm{~m} \Omega$ \\
\hline$C_{b}$ (DC bus capacitance) & $1.1 \mathrm{mF}(\mathrm{KEMET})$ \\
\hline
\end{tabular}

\subsection{Proposed System Design}

The proposed BBBC system is designed in Altium Designer ${ }^{\circledR}$ software. The foremost components used in the constructed experimental prototype, the digital controller, as well as the system parameters are summarized in Table 1. The experimental test bench is based on the schematic diagram of Figure 4 .

As the constructed converter is a scaled-down version of the one that would be used on the actual DC distribution network of an aircraft, the DC bus voltage level of the converter is selected to be $120 \mathrm{~V}$. Also, the DC bus impedance value has been properly scaled down, in order to effectively implement the desired voltage transients with lower current values, compared to the ones found in an actual $\mathrm{M} / \mathrm{A}-\mathrm{EA}$ system. The impedance calculation is based on various previous works that take into account the equivalent impedance of the generators, the TRUs, and the cables [32-36]. Finally, the initial voltage level of the supercapacitor bank is chosen to be $50 \mathrm{~V}$. As it was mentioned earlier, the chosen capacity is overwhelming for the specific test bench, as it reflects a much higher support-BBBC design. Based on simulation and experimental results, the voltage drop/raise of the supercapacitor-bank during the voltage support operation of the system is less than $1 \mathrm{~V}$, indicating that the chosen capacity is not optimal for the current test bench. Nevertheless, with the selected initial supercapacitors voltage 
(i.e., $50 \mathrm{~V}$ ) the proposed system is able to effectively compensate both voltage sags and swells, operating in both boost and buck mode, respectively.

\section{Simulation and Experimental Verification}

In order the functionality and the effective voltage transient mitigation of the above described system to be validated, simulations and experiments have been performed. In this section, simulation and experimental results are presented.

\subsection{Simulation Results}

Regarding the simulations, a model of the proposed system is developed via MATLAB ${ }^{\circledR} /$ Simulink $^{\circledR}$ software package, which is based on the schematic diagram of Figure 4 and the parameters of Table 1. Firstly, in Figure 7, the operating principle of the BBBC is explained, for both boost (in case of voltage sag) and buck (in case of voltage swell) modes, where the load current (before and after the LPF, with the cutoff frequency $f_{c}$ at $1 \mathrm{~Hz}$ ) is depicted, along with the derived BBBC current reference.
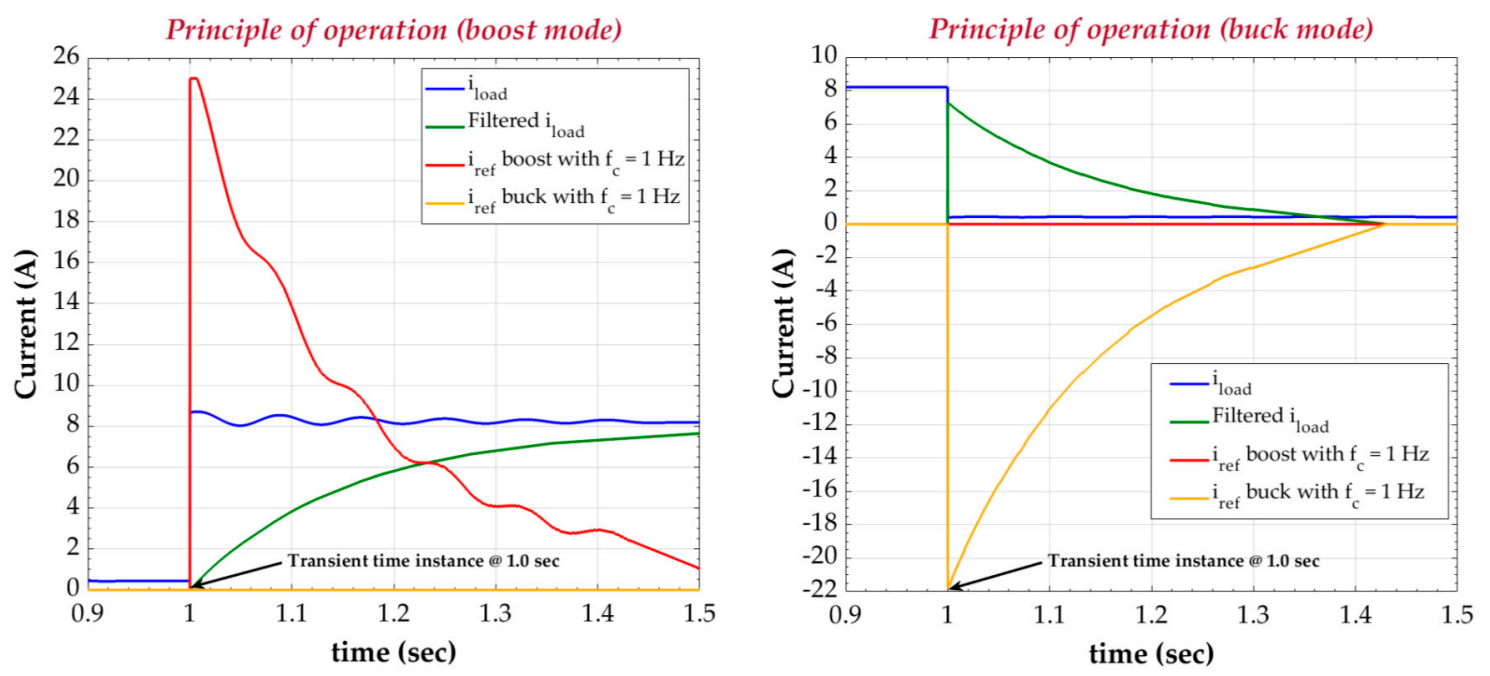

Figure 7. Principle of operation of the proposed system, for boost and buck modes.

In boost mode the current reference is assumed positive, whereas in buck mode negative. Finally, a step in load is considered at $1 \mathrm{~s}$, for each simulation case. For a voltage sag, the load changes from $0.5 \mathrm{~A}$ to $8.2 \mathrm{~A}$, and vice-versa for a voltage swell.

In Figures 8 and 9 the DC bus voltage profile is given, for both a voltage sag (forcing the BBBC in boost mode) and a voltage swell (forcing the BBBC in buck mode), occurring after the load step change. A comparison of the DC bus voltage profile for three different cutoff frequency values for the LPF of the controller of Figure 4 (i.e., $1 \mathrm{~Hz}, 2 \mathrm{~Hz}$ and $5 \mathrm{~Hz}$ ) is also presented.

Based on the presented results we can conclude that the BBBC operation with $1 \mathrm{~Hz}$ LPF cutoff frequency mitigates the voltage transients sufficiently (for both buck and boost operation), maintaining the bus voltage within the region for normal transients, defined in MIL-STD-704F standard. The load current and the BBBC inductor reference current with the LPF cutoff frequency as a parameter are depicted in Figures 10 and 11, for the voltage sag and voltage swell test case, respectively. 


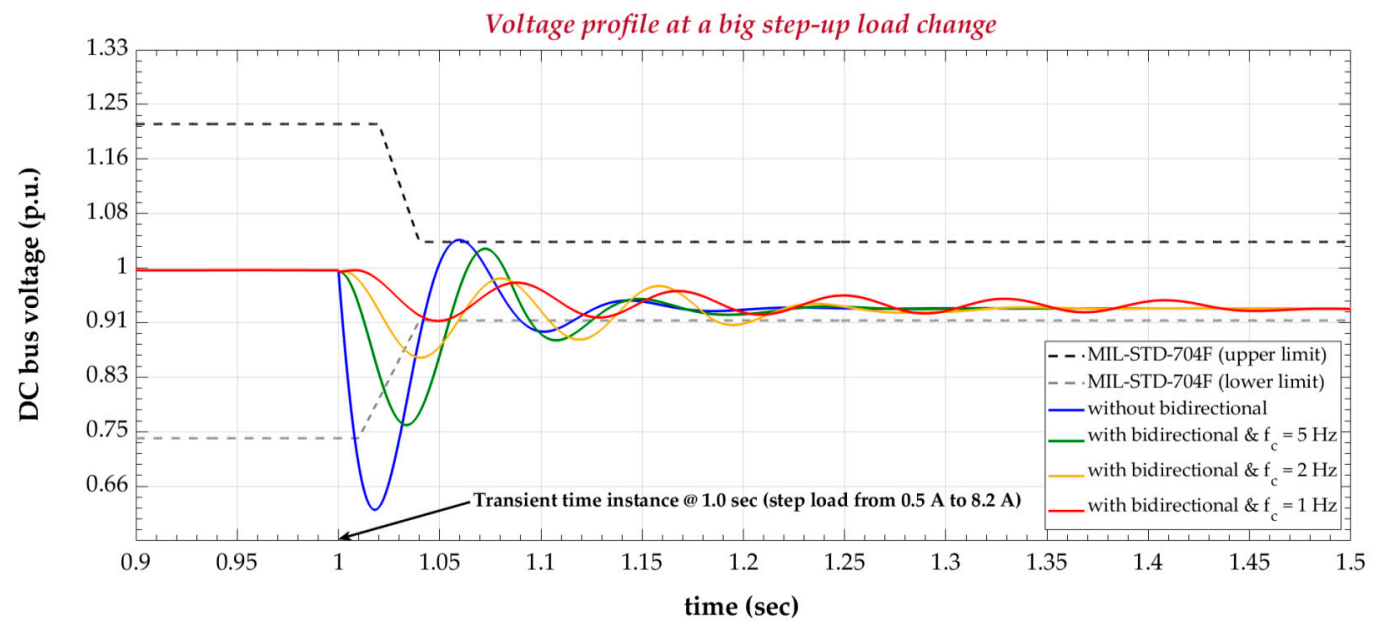

Figure 8. DC bus voltage response for a voltage sag, with the LPF cutoff frequency as a parameter.

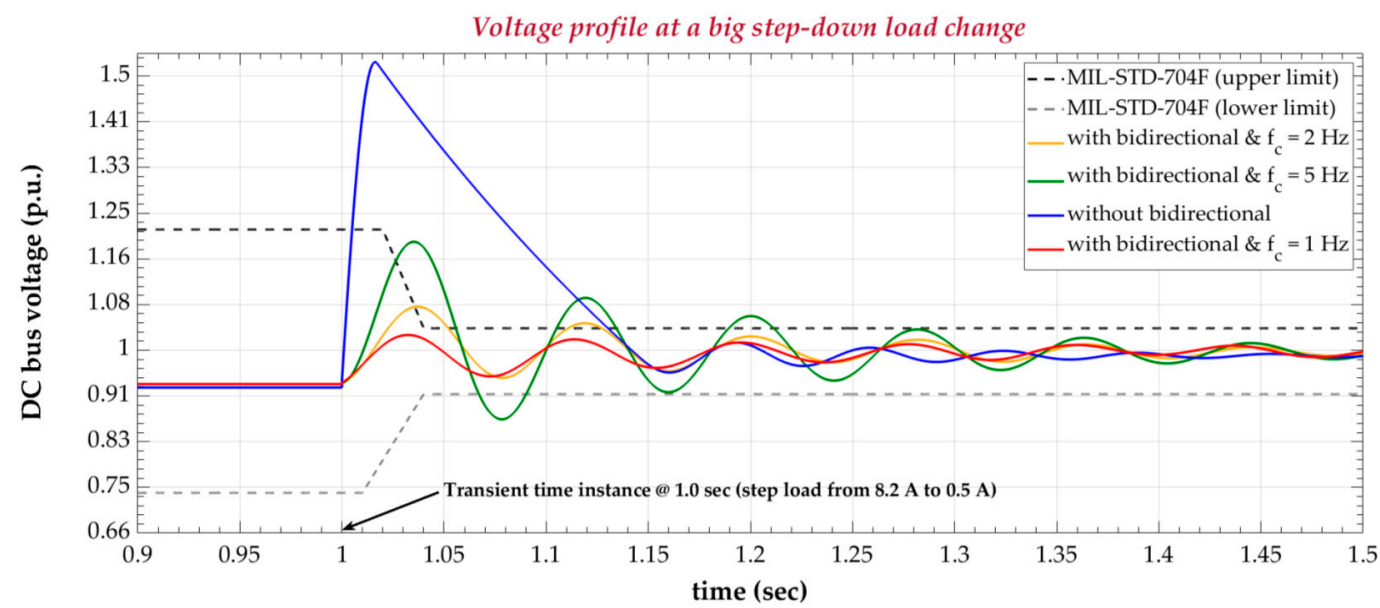

Figure 9. DC bus voltage response for a voltage swell, with the LPF cutoff frequency as a parameter.

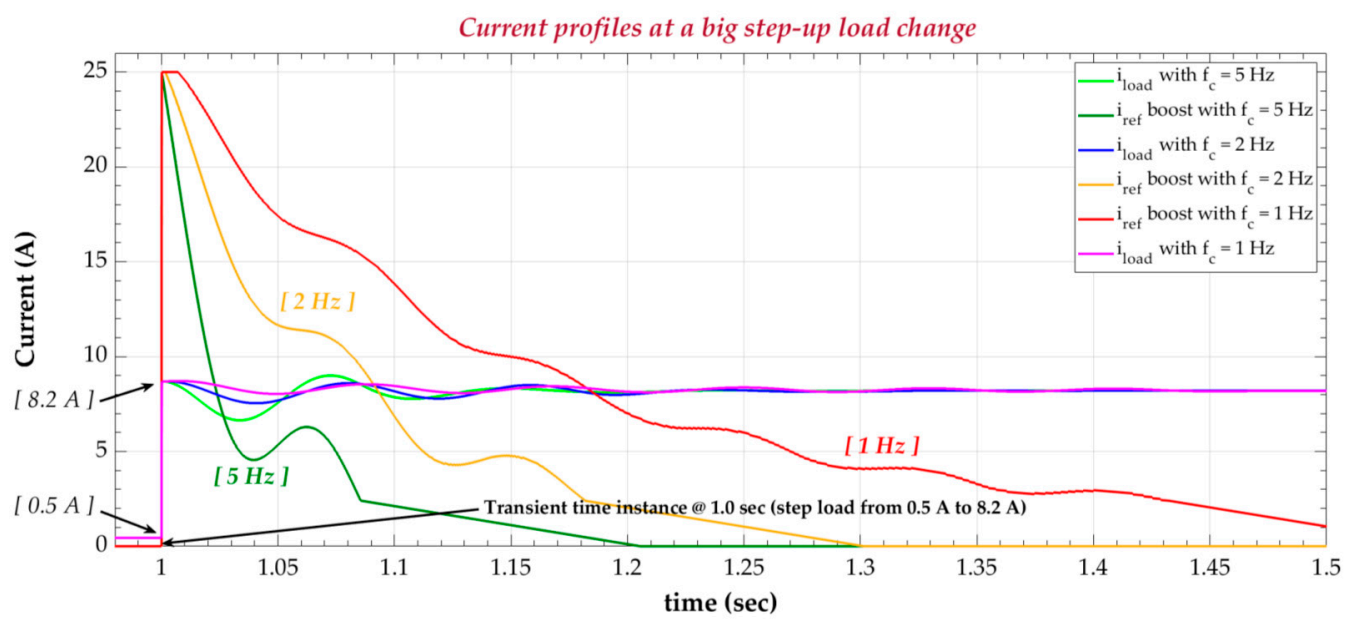

Figure 10. Load current and inductor current reference for a voltage sag case, with LPF cutoff frequency as a parameter. 


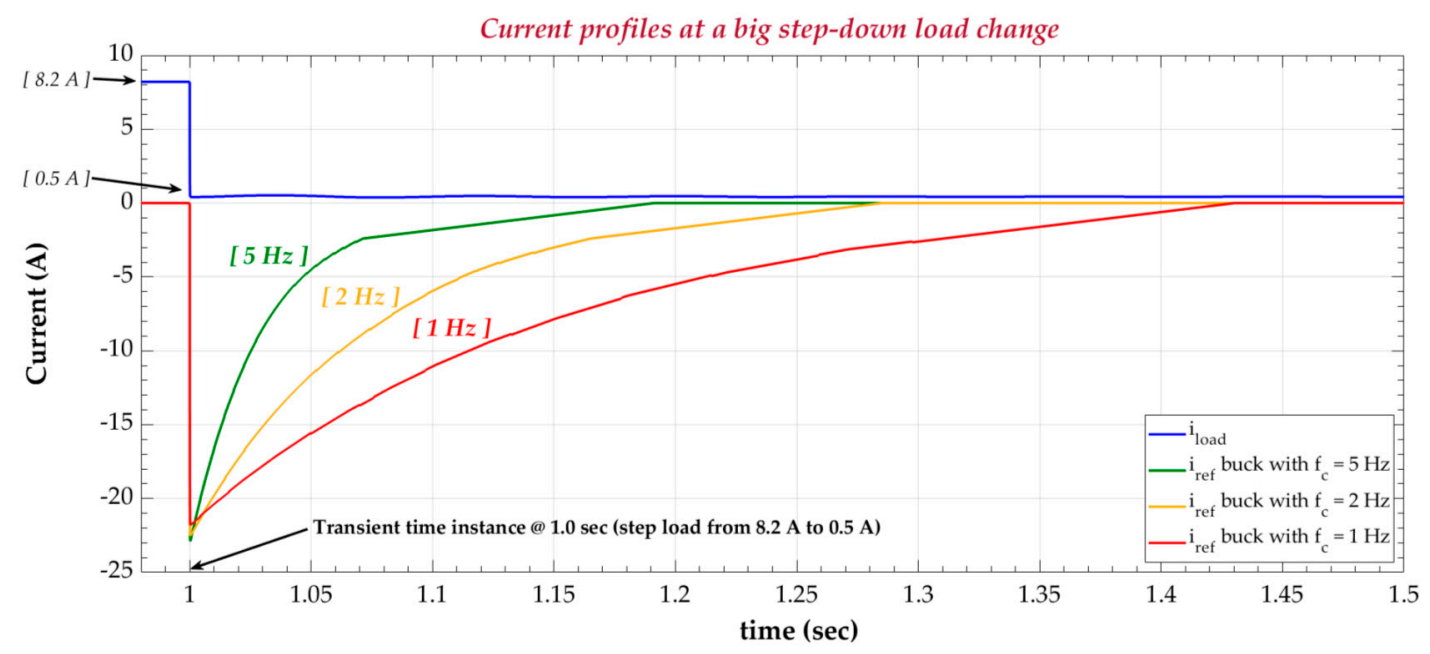

Figure 11. Inductor current reference for a voltage swell case, with LPF cutoff frequency as a parameter.

The inductor current (as well as the total converter current reference) is inversely proportional to the LPF cutoff frequency, implying that a cutoff frequency of $f_{c}=1 \mathrm{~Hz}$ will force the BBBC to operate for a longer duration, as such providing more energy to the DC bus, with respect to the $f_{c}=2 \mathrm{~Hz}$ and $f_{c}=5 \mathrm{~Hz}$, accordingly. Hence, the lower the LPF cutoff frequency, the higher the total energy losses of the system are, as it is presented in Figure 12. In more detail, the total amount of energy losses is approximately $5 \mathrm{~J}$, for the case of $f_{c}=1 \mathrm{~Hz}$, whereas this amount is decreased by $54.7 \%$ and by $82.4 \%$, for the cases of $f_{c}=2 \mathrm{~Hz}$ and $f_{c}=5 \mathrm{~Hz}$, respectively. In parallel, both the inductor and semiconductor switches losses play a major role to the total amount of the system power losses, with a percentage of approximately $50 \%$ for the inductor and $46 \%$ for the MOSFETs power losses, while the rest $(4 \%)$ portion, corresponds to the supercapacitor bank conduction losses.
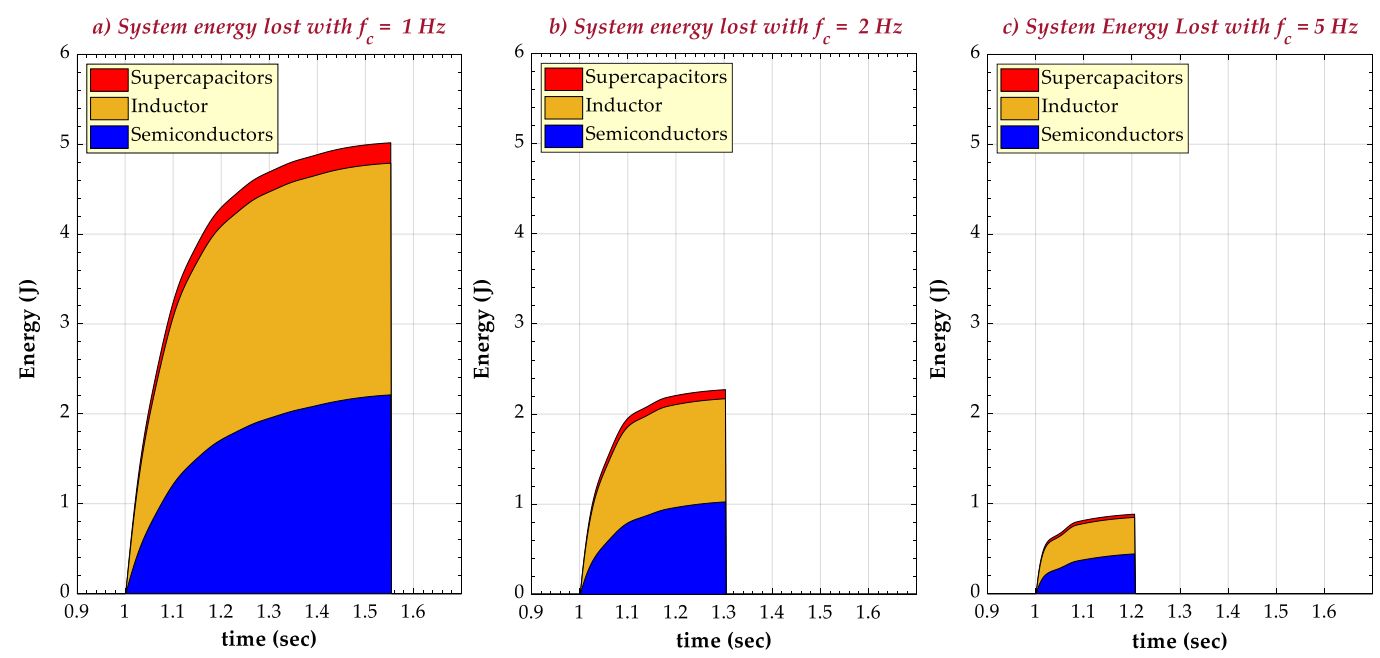

Figure 12. System energy losses for LPF cutoff frequency values of (a) $1 \mathrm{~Hz},(\mathbf{b}) 2 \mathrm{~Hz}$ and (c) $5 \mathrm{~Hz}$.

It is worth noting that the energy losses have been calculated in boost mode of operation of the BBBC (voltage sag case), considering the analysis presented in Section 3.4, in respect to the datasheet parameters [28], without the addition of compensation ramp (worst-case scenario). The estimated efficiency of the system in boost operation (voltage sag case) as a function of the BBBC output current is depicted in Figure 13. 


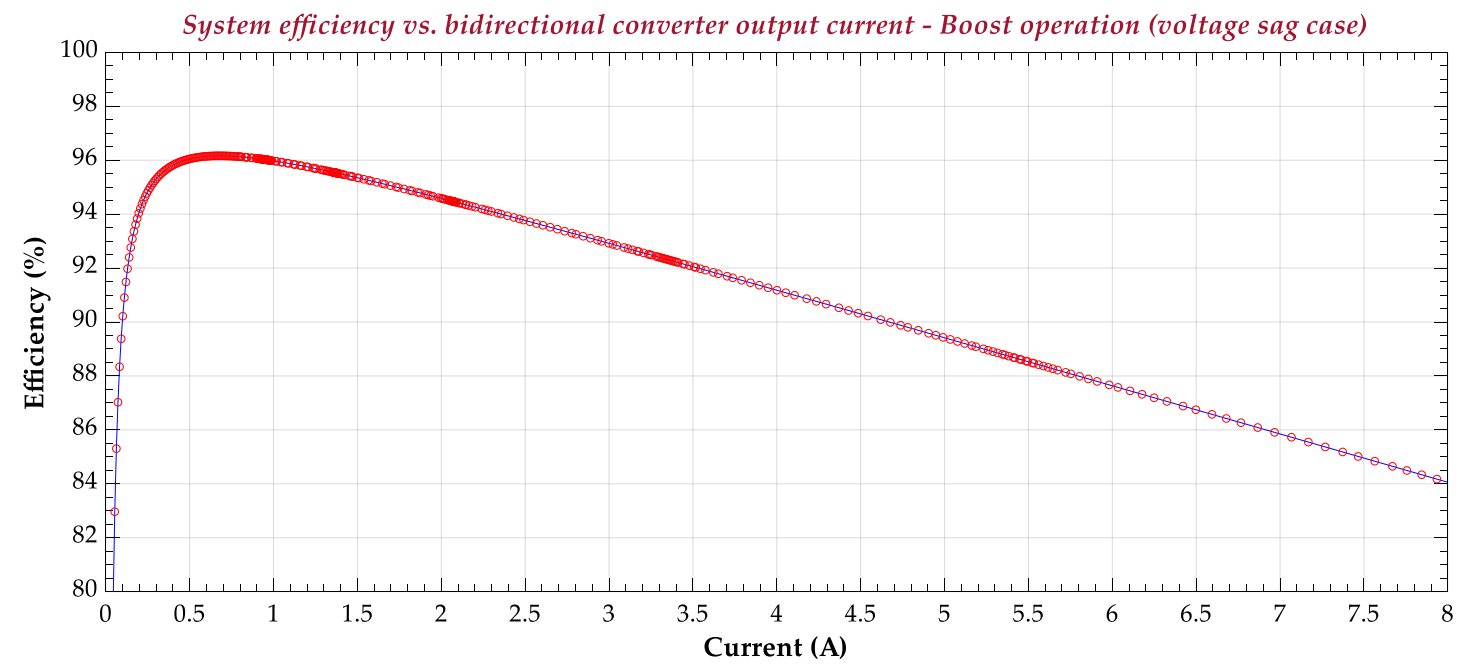

Figure 13. Estimated system efficiency for boost operation (voltage sag case), with the BBBC output current as a parameter.

Finally, Figure 14 indicates the effective voltage compensation and compliance with the MIL-STD-704F normal voltage transient limits in the worst-case scenario of a double transient condition, where a voltage swell is followed by a voltage sag, occurring at $1 \mathrm{~s}$ and $1.3 \mathrm{~s}$, respectively. Both DC bus voltage and current profiles are depicted.
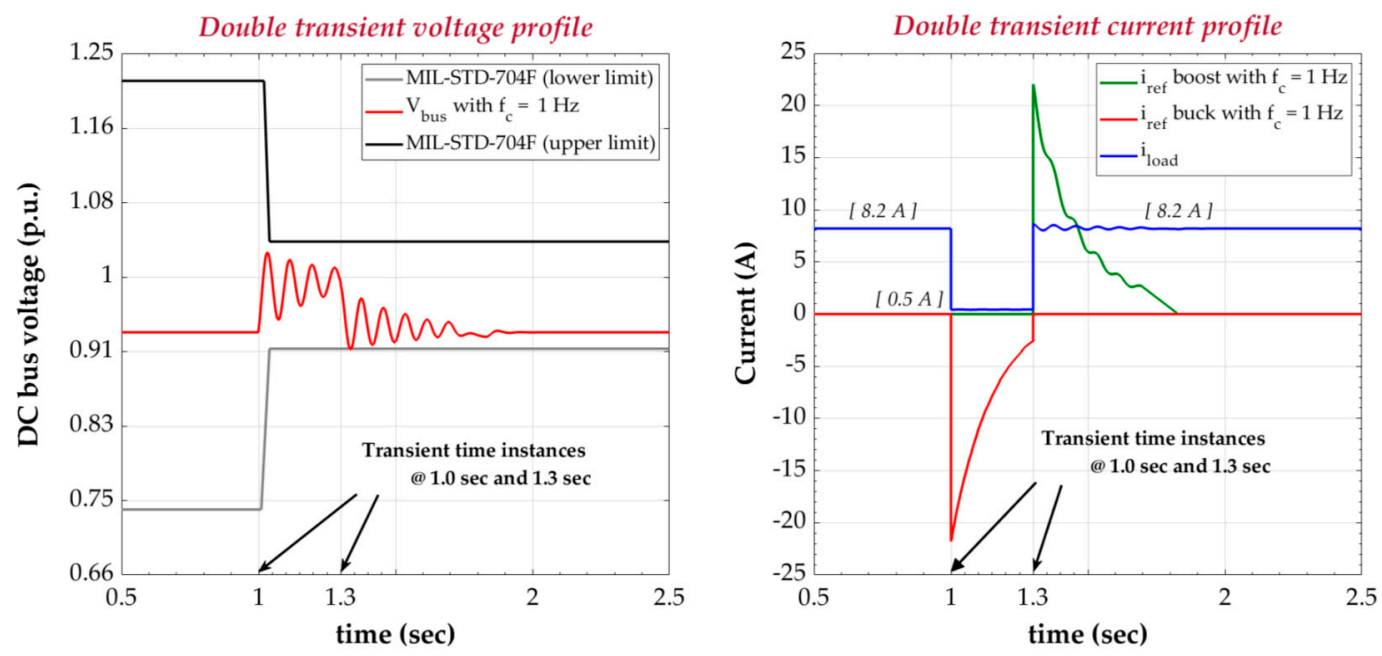

Figure 14. DC bus voltage and current profiles for a double voltage transient.

\subsection{Experimental Results}

Experiments on a laboratory test bench have been carried out for the same load steps that have been considered in the simulations subsection, evaluating the impact of the LPF cutoff frequency as well, in order to experimentally investigate the proposed system performance. Indicative results are provided in Figures 15 and 16.

Specifically, the DC bus voltage profile is shown in Figure 15, during a voltage sag (caused by a load step increase), considering a LPF cutoff frequency of $1 \mathrm{~Hz}, 2 \mathrm{~Hz}$ and $5 \mathrm{~Hz}$. In Figure 16 the DC bus voltage profile is depicted, over a voltage swell (caused by a load step decrease), along with the respective fc values. Finally, for comparison purposes, the DC bus voltage response without the proposed system is included both in Figures 15 and 16.

Based on the experimental results presented in Figures 15 and 16, we conclude that the BBBC operation with $f_{c}=1 \mathrm{~Hz}$ is superior to the $2 \mathrm{~Hz}$ and $5 \mathrm{~Hz}$ operation (confirming so the simulation 
results), and that it may effectively mitigate voltage transients, supporting the DC bus voltage, in order to remain within the defined envelope for normal transients, according to MIL-STD-704F.
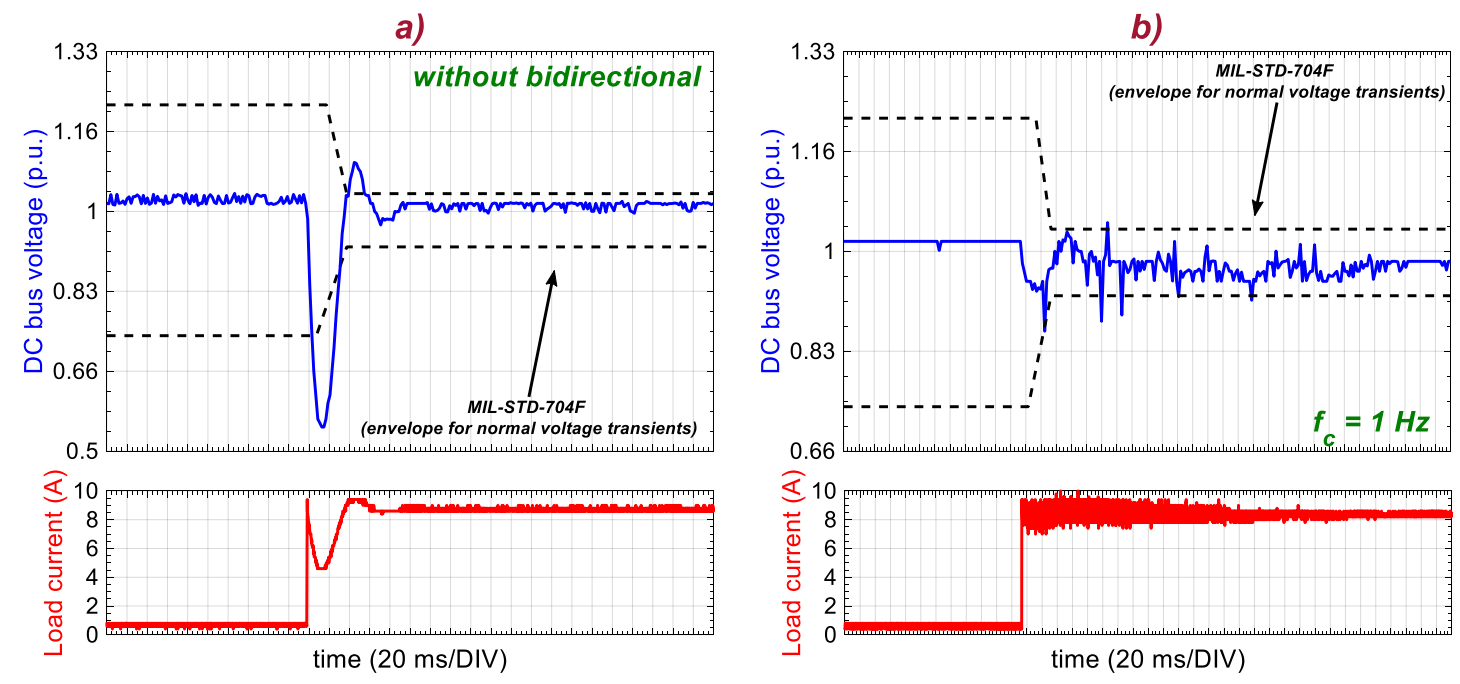

c)
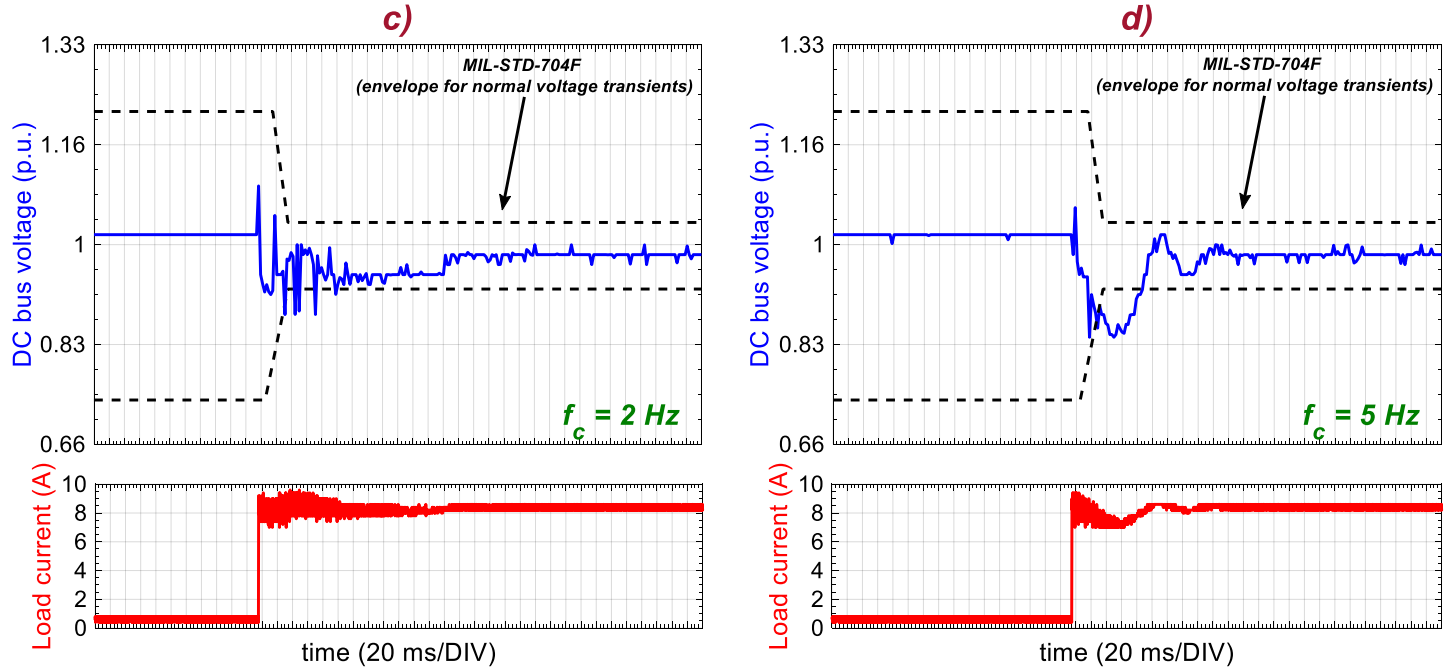

Figure 15. DC bus voltage response for a voltage sag, with the LPF cutoff frequency as a parameter, (a) without the proposed system; (b) $f_{c}=1 \mathrm{~Hz} ;(\mathbf{c}) f_{c}=2 \mathrm{~Hz}$; (d) $f_{c}=5 \mathrm{~Hz}$. 
a)

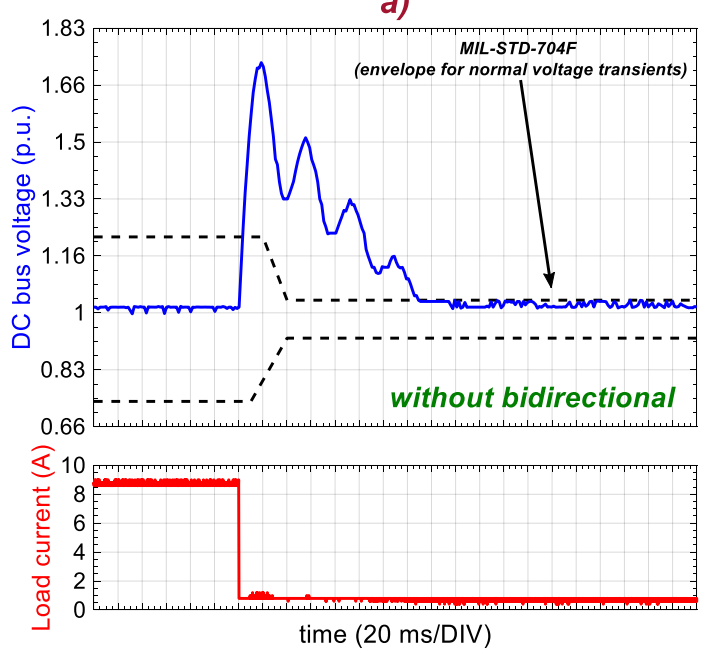

c)

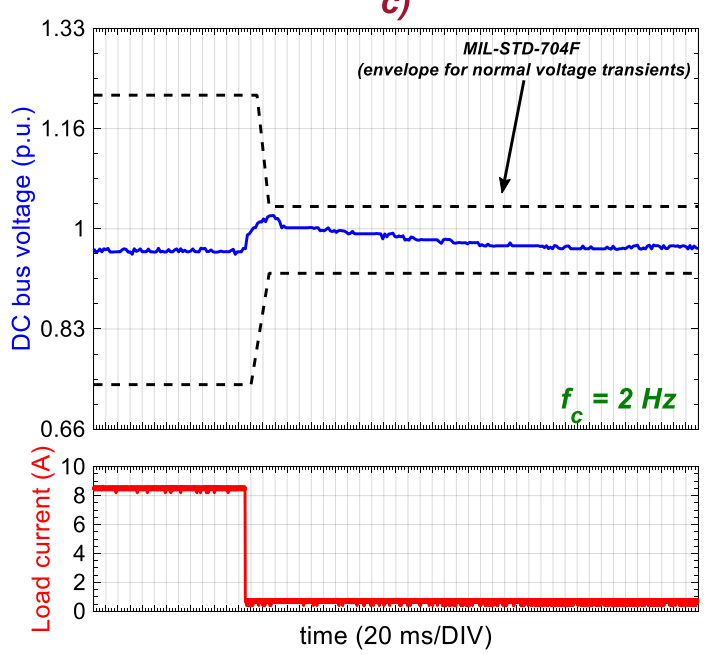

b)

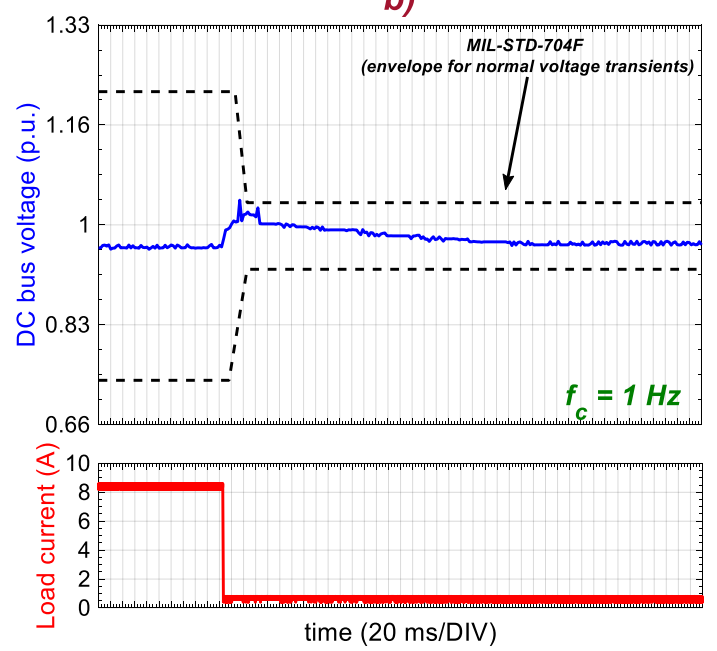

d)

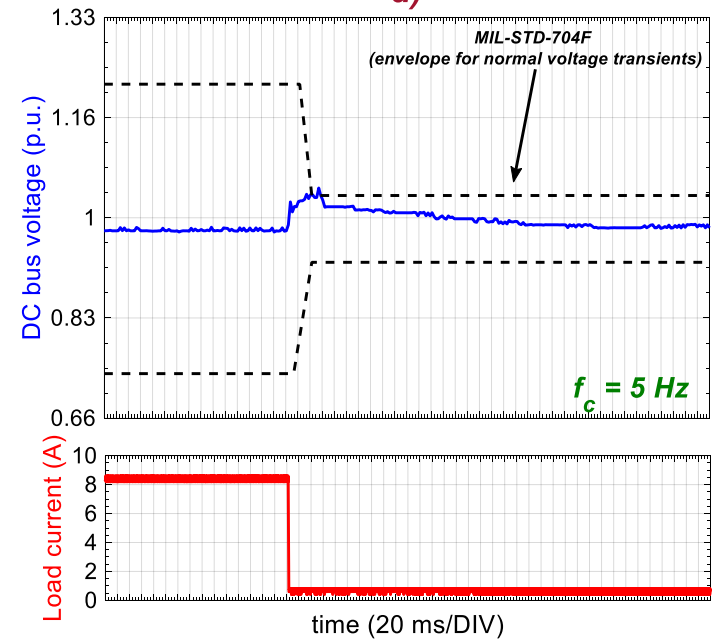

Figure 16. DC bus voltage response for a voltage swell, with the LPF cutoff frequency as a parameter, (a) without the proposed system; (b) $f_{c}=1 \mathrm{~Hz} ;(\mathbf{c}) f_{c}=2 \mathrm{~Hz} ;(\mathbf{d}) f_{c}=5 \mathrm{~Hz}$.

\section{Conclusions}

In this work a power conversion system is presented, aiming to effectively mitigate voltage transients that occur on the DC bus of an on-board distribution network. The proposed system comprises a bidirectional converter (BBBC) and a supercapacitor bank, along with a PCC-based controller and a supervisor to implement the proposed concept. The foremost circuitries of the converter, being the power stage $\mathrm{SiC}$ switches and the driving circuit are both implemented with $\mathrm{ON}$ Semiconductor parts.

The DC bus voltage profile improvement that can be achieved with the proposed system in cases of voltage transients, has been verified through both simulation and experimental results. Last but not least, keeping the DC bus voltage within the normal transient limits highlights the MIL-STD-704F standard compliance that can be achieved with the aid of the proposed system. To conclude, this work as a whole aims to contribute to the challenging issue of voltage compensation techniques and power quality maintenance, concerning the on-board microgrids of M/A-EAs, which will be the dominant technology for future civil aircrafts.

Author Contributions: Conceptualization, N.R. and N.P.; methodology, N.R., D.V., T.J. and N.P.; software, N.R. and D.V.; validation, N.R., D.V., T.J. and N.P.; formal analysis, N.R., D.V., T.J. and N.P.; investigation, N.R., D.V. and T.J.; resources, N.R., D.V. and T.J.; data curation, N.R. and D.V.; writing-original draft preparation, N.R.; writing-review and editing, N.R., D.V., T.J. and N.P.; visualization, N.R.; supervision, N.P.; All authors have read and agreed to the published version of the manuscript. 
Funding: This research received no external funding.

Acknowledgments: The authors would like to acknowledge the support of ON Semiconductor for providing the semiconductor switches and all required drivers and ICs for the hardware implementation of the proposed solution.

Conflicts of Interest: The authors declare no conflict of interest.

\section{Nomenclature}

\section{Abbreviations}

AC

APU

ATRU

BBBC

CCM

DC

DCM

ESR

HVDC

M/A-EA

MEA

MOSFET

PCC

PWM

RMS

$\mathrm{SiC}$

SSPC

TRU

Symbols

$C_{b}$

$\mathrm{C}_{\mathrm{HV}}$

$\mathrm{C}_{S C}$

$d$

$E_{\text {off }}$

$E_{\text {on }}$

$f_{s}$

$i_{b u s}$

$i_{c}$

$i_{\text {conv }}$

$I_{D}$

$I_{D, r m s}$

$I_{\text {HIGH }}$

$I_{L}$

$I_{L, \max }$

$I_{L, \min }$

$I_{L, r m s}$

$i_{\text {load }}$

I LOW

k

L

$L_{b}$

$m_{1}$

$m_{c}$

$P_{\text {cond }}$

$P_{\text {HIGH }}$

$P_{\text {ind }}$

$P_{\text {losses }}$
Alternating Current

Auxiliary Power Unit

Auto-Transformer Rectifier Unit

Bidirectional Buck-Boost Converter

Continuous Conduction Mode

Direct Current

Discontinuous Conduction Mode

Equivalent Series Resistance

High Voltage Direct Current

More/All Electric Aircraft

More Electric Aircraft

Metal Oxide Semiconductor Field Effect Transistor

Peak Current Control

Pulse Width Modulation

Root Mean Square

Silicon Carbide

Solid State Power Controller

Transformer Rectifier Unit

DC bus capacitance

Bidirectional converter high voltage side capacitance

Supercapacitor bank capacitance

Bidirectional converter duty ratio

Energy dissipated during turn-off transition

Energy dissipated during turn-on transition

Bidirectional converter switching frequency

DC bus current (supplied to load)

Control signal (peak current reference)

Bidirectional converter current (source/sink to/from the DC bus)

Average value of the MOSFET drain current

RMS value of the MOSFET drain current

Average value of the bidirectional converter high voltage side current

Average value of the inductor current

Maximum value of the inductor current

Minimum value of the inductor current

RMS value of the inductor current

Load current

Average value of the bidirectional converter low voltage side current

Current reference multiplication factor (bidirectional converter gain)

Bidirectional converter inductance

DC bus inductance

Rising slope of the inductor current

Compensation ramp slope

MOSFET conduction power losses

Average power at the bidirectional converter high voltage side

Inductor conduction power losses

Total system power losses 
$P_{\text {LOW }} \quad$ Average power at the bidirectional converter low voltage side

$P_{\text {scaps }} \quad$ Supercapacitor bank conduction power losses

$P_{\text {semi }} \quad$ MOSFET power losses

$P_{s w} \quad$ MOSFET switching power losses

$P_{\text {turn-off }} \quad$ Switching power losses during turn-off transition

$P_{\text {turn-on }} \quad$ Switching power losses during turn-on transition

$Q_{r} \quad$ Recovered stored charge of the antiparallel diode

$R_{b} \quad$ DC bus resistance

$R_{D S(o n)} \quad$ MOSFET drain-source on-resistance

$R_{L}$

$R_{\text {Load }}$

Resistance of the bidirectional converter inductor

$R_{\text {scaps }}$

Load resistance

$S_{\text {high }}$

Supercapacitor bank resistance

$S_{\text {low }}$

$t_{\text {off }}$

$t_{r}$

$T_{s}$

$V_{b}$

$V_{D S}$

$V_{\text {HIGH }}$

$V_{\text {LOW }}$

$V_{S C}$

$V_{S C(\max )}$

Upper bidirectional converter MOSFET (controlled in buck mode)

Lower bidirectional converter MOSFET (controlled in boost mode)

Turn-off transition time interval

Turn-on transition time interval

Bidirectional converter switching period

DC bus voltage

MOSFET drain-source voltage

$\Delta I_{L}$

Average voltage at the bidirectional converter high voltage side

Average voltage at the bidirectional converter low voltage side

Supercapacitors voltage

$\Delta I_{L, 0}$

Supercapacitors maximum voltage

Inductor current disturbance

$\Delta I_{L, 1}$

Initial (first cycle) small disturbance in the inductor current

$\Delta I_{L, 2}$

Small disturbance in the inductor current at the second switching cycle

$\Delta V_{\text {on }}$

Small disturbance in the inductor current at the third switching cycle

Voltage drop of the MOSFET antiparallel diode during its conduction

\section{Appendix A}

A schematic diagram of the PCC technique with the addition of a compensation ramp is depicted in Figure A1. It is noted that in this figure the compensation ramp slope is improperly calculated, on purpose, in order to highlight the fact that the inductor current disturbance $\left(\Delta I_{L}\right)$ can be amplified, after a couple of switching cycles, thus the impact of the compensation ramp slope $\left(m_{c}\right)$ has to be verified.

\section{current}

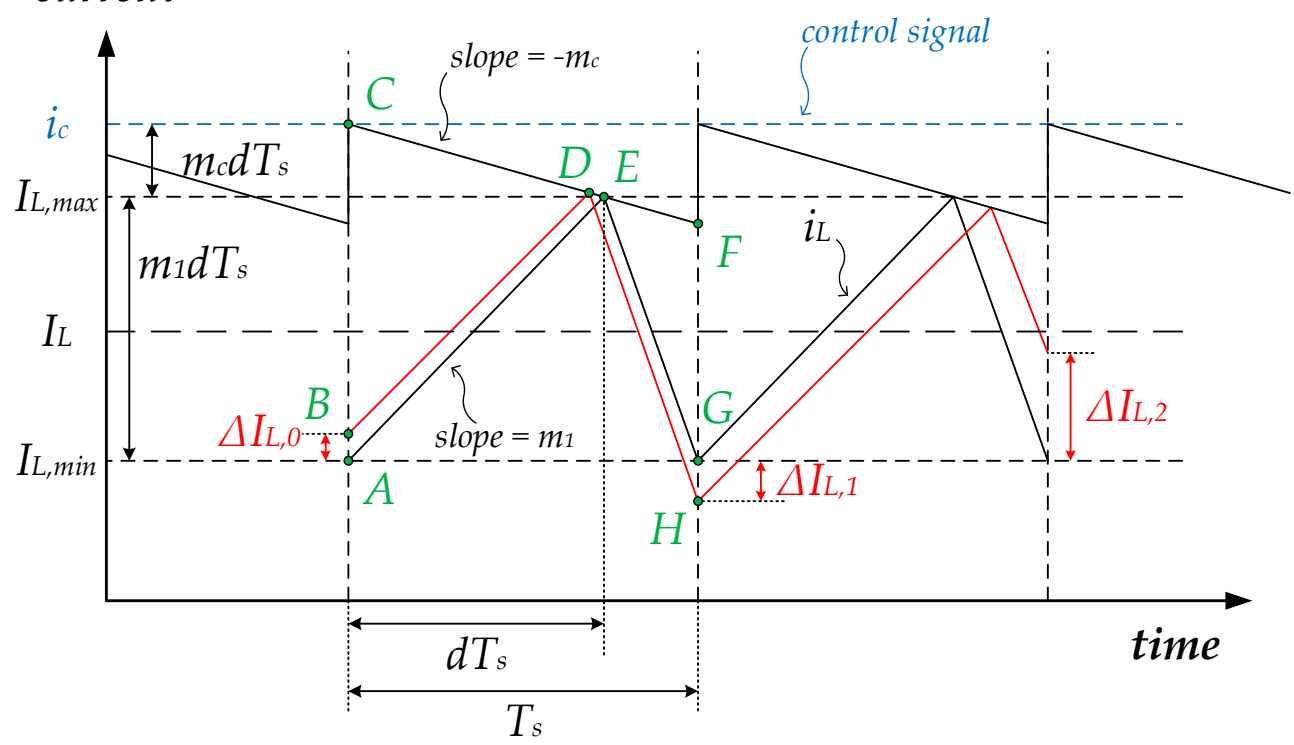

Figure A1. Schematic diagram of the peak current control technique with the addition of an improperly calculated compensation ramp. 
Assuming a small disturbance $\left(\Delta I_{L, 0}\right)$ in the inductor current, it turns out that the line segment AE is parallel to $\mathrm{BD}$ and respectively $\mathrm{DH}$ is parallel to $\mathrm{EG}$, according to Figure $\mathrm{A} 1$. Hence, the triangle $\mathrm{BCD}$ is similar to $\mathrm{ACE}$, whereas the triangle GFE is similar to HFD and thus it is obtained:

$$
\left\{\begin{array}{l}
\frac{\Delta I_{L, 0}}{A C}=\frac{E D}{E C} \\
\frac{E D}{F D}=\frac{\Delta I_{L, 1}}{F G}
\end{array} .\right.
$$

It is noted that the absolute value is considered, for the inductor current disturbances $\left(\Delta I_{L, 0}\right.$ and $\left.\Delta I_{L, 1}\right)$ in Equation (A1). As such, it does not matter, whether the sign of the current disturbance is positive or negative. Hence it is derived:

$$
\left\{\begin{array}{l}
E D=E C \frac{\Delta I_{L, 0}}{A C} \\
E D=F D \frac{\Delta I_{L, 1}}{F G}
\end{array} .\right.
$$

By merging the two Equations in (A2), it is acquired:

$$
\Delta I_{L, 1}=\frac{E C \cdot F G}{A C \cdot F D} \Delta I_{L, 0}
$$

However, with the aid of Figure A1 it is easily obtained:

$$
\frac{F G}{F D}=\frac{d}{1-d}
$$

And thus, it is derived:

$$
\Delta I_{L, 1}=\frac{m_{1} d T_{s}-m_{\mathcal{c}}(1-d) T_{s}}{\left(m_{1}+m_{c}\right) d T_{S}} \cdot \frac{d}{1-d} \Delta I_{L, 0} .
$$

In order to avoid the subharmonic oscillations, it is required:

$$
\Delta I_{L, 1} \leq \Delta I_{L, 0} .
$$

Substituting Equation (A5) into Equation (A6), it is obtained:

$$
\frac{m_{1} d T_{s}-m_{\mathcal{c}}(1-d) T_{s}}{\left(m_{1}+m_{\mathcal{c}}\right) d T_{s}} \cdot \frac{d}{1-d} \leq 1
$$

Hence, after mathematical manipulations, it is derived:

$$
m_{c} \geq m_{1} \cdot \frac{2 d-1}{2(1-d)}
$$

The slope of the compensation ramp may be set to zero (its minimum value) for $d<0.5$, whereas for $d \geq 0.5$ the condition, in order to eliminate the subharmonic oscillations, is given in Equations (A9) and (A10), by substituting the slope $m_{1}$ value into Equation (A8) for boost (supercapacitors discharging) and buck (supercapacitors charging) operation, respectively:

$$
\begin{aligned}
& m_{C} \geq\left\{\begin{array}{ll}
0, & d<0.5 \\
\frac{V_{\text {LOW }}}{L} \cdot \frac{2 d-1}{2(1-d)}, & d \geq 0.5
\end{array} \quad\right. \text { (Boost), }
\end{aligned}
$$

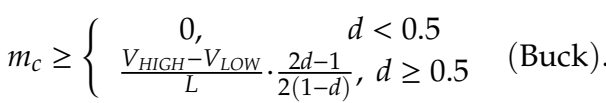

Last but not least, it is worth noting that at the design stage a safety margin is usually applied by a rule of thumb (e.g., 20\%) at the above slope value, so as the compensation ramp to sufficiently suppress subharmonic oscillations over a wide operating range.

\section{References}

1. Bozhko, S.; Hill, C.I.; Yang, T. More-Electric Aircraft: Systems and Modeling. Wiley Encycl. Electr. Electron. Eng. 2018, 1-31. [CrossRef]

2. Madonna, V.; Migliazza, P.; Giangrande, P.; Lorenzani, E.; Buticchi, G.; Galea, M. The Rebirth of the Current Source Inverter: Advantages for Aerospace Motor Design. IEEE Ind. Electron. Mag. 2019, 13, 65-76. [CrossRef] 
3. European Commission. Flightpath 2050. Europe's Vision for Aviation. 2011. Available online: https: //ec.europa.eu/transport/sites/transport/files/modes/air/doc/flightpath2050.pdf (accessed on 7 August 2020).

4. Buticchi, G.; Costa, L.; Lissere, M. Improving System Efficiency for the More Electric Aircraft: A Look at $\mathrm{dc} / \mathrm{dc}$ Converters for the Avionic Onboard dc Microgrid. IEEE Ind. Electron. Mag. 2017, 11, 26-36. [CrossRef]

5. Buticchi, G.; Costa, L.F.; Barater, D.; Lissere, M.; Amarillo, E.D. A Quadruple Active Bridge Converter for the Storage Integration on the More Electric Aircraft. IEEE Trans. Power Electron. 2018, 33, 8174-8186. [CrossRef]

6. Chen, J.; Song, Q.; Yin, S.; Chen, J. On the Decentralized Energy Management Strategy for the All-Electric APU of Future More Electric Aircraft Composed of Multiple Fuel Cells and Supercapacitors. IEEE Trans. Ind. Electron. 2020, 67, 6183-6194. [CrossRef]

7. Todd, R.; Forsyth, A.J. DC-bus power quality for aircraft power systems during generator fault conditions. IET Electr. Syst. Transp. 2011, 1, 126-135. [CrossRef]

8. Chen, J.; Wang, C.; Chen, J. Investigation on the Selection of Electric Power System Architecture for Future More Electric Aircraft. IEEE Trans. Transp. Electr. 2018, 4, 563-576. [CrossRef]

9. Sarlioglu, B.; Morris, C.T. More Electric Aircraft: Review, Challenges, and Opportunities for Commercial Transport Aircraft. IEEE Trans. Transp. Electr. 2015, 1, 54-64. [CrossRef]

10. The Air Transport System and Clean Sky. The Hub of Europe's Aeronautical R\&T. 2004. Available online: https://www.cleansky.eu/aviation-0 (accessed on 7 August 2020).

11. Yang, T.; Bozhko, S.; Asher, G. Application of Dynamic Phasor Concept in Modeling Aircraft Electrical Power Systems. SAE Int. J. Aerosp. 2013, 6, 38-48. [CrossRef]

12. Dragicevic, T.; Lu, X.; Vasquez, J.C.; Guerrero, J.M. DC Microgrids-Part II: A Review of Power Architectures, Applications, and Standardization Issues. IEEE Trans. Power Electron. 2016, 31, 3528-3549. [CrossRef]

13. Dragicevic, T.; Vasquez, J.C.; Guerrero, J.M.; Skrlec, D. Advanced LVDC Electrical Power Architectures and Microgrids: A step toward a new generation of power distribution networks. IEEE Electrif. Mag. 2014, 2, 54-65. [CrossRef]

14. Elsayed, A.T.; Mohamed, A.A.; Mohammed, O.A. DC Microgrids and distribution systems: An overview. Electric. Power Syst. Res. 2015, 119, 407-417. [CrossRef]

15. Baros, D.; Voglitsis, D.; Papanikolaou, N.; Kyritsis, A.; Rigogiannis, N. Wireless Power Transfer for Distributed Energy Sources Exploitation in DC Microgrids. IEEE Trans. Sustain. Energy 2019, 10, 2039-2049. [CrossRef]

16. Kumar, D.; Zare, F.; Ghosh, A. DC Microgrid Technology: System Architectures, AC Grid Interfaces, Grounding Schemes, Power Quality, Communication Networks, Applications, and Standardizations Aspects. IEEE Access 2017, 5, 12230-12256. [CrossRef]

17. Yang, T.; Gao, F.; Bozhko, S.; Wheeler, P. Power Electronic Systems for Aircraft. In Control of Power Electronic Converters and Systems Vol. 2, 1st ed.; Blaabjerg, F., Ed.; Academic Press: Cambridge, MA, USA, 2018; pp. 333-368. [CrossRef]

18. Department of Defense Interface Standard, MIL-STD-704F, Aircraft Electric Power Characteristics, March 2004. Available online: http://everyspec.com/MIL-STD/MIL-STD-0700-0799/MIL-STD-704F_1083/ (accessed on 7 August 2020).

19. Karatzaferis, I.; Tatakis, E.; Papanikolaou, N. Analysis and design of a universal energy recovery converter for use with industrial inverters. In Proceedings of the 9th International Conference on Compatibility and Power Electronics (CPE 2015), Costa da Caparica, Portugal, 24-26 June 2015. [CrossRef]

20. Kyritsis, A.; Papanikolaou, N.; Tatakis, E. Enhanced current pulsation smoothing parallel active filter for single stage grid-connected AC-PV modules. In Proceedings of the 13th International Power Electronics and Motion Control Conference (EPE 2008), Poznan, Poland, 1-3 September 2008. [CrossRef]

21. Karatzaferis, I.; Tatakis, E.; Papanikolaou, N. Investigation of energy savings on industrial motor drives using bidirectional converters. IEEE Access 2017, 5, 17952-17961. [CrossRef]

22. Rigogiannis, N.; Voglitis, D.; Papanikolaou, N. Microcontroller Based Implementation of Peak Current Control Method in a Bidirectional Buck-Boost DC-DC Converter. In Proceedings of the 20th International Symposium on Electrical Apparatus and Technologies (SIELA 2018), Bourgas, Bulgaria, 3-6 June 2018. [CrossRef]

23. Erickson, R.W.; Maksimovic, D. Fundamentals of Power Electronics, 3rd ed.; Springer Nature Switzerland AG: Cham, Switzerland, 2020. [CrossRef]

24. Ridley, R.B. A New, Continuous-Time Model for Current-Mode Control. IEEE Trans. Power Electron. 1991, 6 , 271-280. [CrossRef] 
25. Hallworth, M.; Shirsavar, S.A. Microcontroller-Based Peak Current Mode Control Using Digital Slope Compensation. IEEE Trans. Power Electron. 2012, 3340-3351. [CrossRef]

26. Rigogiannis, N.; Baros, D.; Lempesis, E.; Ntoga, S.; Peioglou, E.; Pechlivanis, C.; Papanikolaou, N. Experimental Investigation of a Digitally Current Controlled Synchronous Buck DC/DC Converter for Microgrids Applications. In Proceedings of the 2019 Panhellenic Conference on Electronics \& Telecommunications (PACET), Volos, Greece, 8-9 November 2019. [CrossRef]

27. Mohan, N.; Undeland, T.M.; Robbins, W.P. Power Electronics: Converters, Applications and Design, 3rd ed.; Wiley: Hoboken, NJ, USA, 2002.

28. ON Semiconductor. Datasheet: NVHL160N120SC1. Silicon Carbide N-Channel MOSFET. Available online: https://www.onsemi.com/pub/Collateral/NVHL160N120SC1-D.pdf (accessed on 7 August 2020).

29. ON Semiconductor. Datasheet: FAN7390. High \& Low Side Gate-Driver. Available online: https: //www.onsemi.com/pub/Collateral/FAN7390-D.pdf (accessed on 7 August 2020).

30. ON Semiconductor. Datasheet: RHRD660S. Hyperfast Diode. Available online: https://www.onsemi.com/ pub/Collateral/RHRD660S-D.pdf (accessed on 7 August 2020).

31. ON Semiconductor. Datasheet: 6N137M. Logic Gate Optocoupler. Available online: https://www.onsemi. com/pub/Collateral/HCPL2631M-D.pdf (accessed on 7 August 2020).

32. Gao, F.; Bozhko, S.; Costabeber, A.; Asher, G.; Wheeler, P. Control Design and Voltage Stability Analysis of a Droop Controlled Electrical Power System for More Electric Aircraft. IEEE Trans. Ind. Electron. 2017, 64, 9271-9281. [CrossRef]

33. Zhang, H.; Mollet, F.; Saudemont, C.; Robyns, B. Experimental Validation of Energy Storage System Management Strategies for a Local DC Distribution System for More Electric Aircraft. IEEE Trans. Ind. Electron. 2010, 57, 3905-3916. [CrossRef]

34. Trentin, A.; Zanchetta, P.; Wheeler, P.; Clare, J. Power Conversion for a Novel AC/DC Aircraft Electrical Distribution System. IET Electr. Syst. Transp. 2014, 4, 29-37. [CrossRef]

35. Gao, F.; Bozhko, S.; Asher, G.; Wheeler, P.; Patel, C. An Improved Voltage Compensation Approach in a Droop-Controlled DC Power System for the More Electric Aircraft. IEEE Trans. Power Electron. 2016, 31, 7369-7383. [CrossRef]

36. Gao, F; Bozhko, S. Modeling and Impedance Analysis of a Single DC Bus-Based Multiple Source Multiple-Load Electrical Power System. IEEE Trans. Transp. Electrif. 2016, 2, 335-346. [CrossRef] 